\title{
EDUCACIÓN SUPERIOR Y ESTRUCTURA SOCIAL EN CHILE: APROXIMACIONES DESDE TRES GRUPOS GENERACIONALES
}

\author{
FELIPE GHIARDO SOTO ${ }^{1}$ \\ ÓSCAR DÁVILA LEÓN ${ }^{2}$
}

\begin{abstract}
RESUMEN
A mediados de la década del 2000, la evidencia indicaba que uno de cada siete estudiantes de educación superior en Chile era la primera generación de sus familias en alcanzar este nivel de estudios. El presente artículo intenta explorar las consecuencias de este proceso sobre la condición socioeconómica de este grupo. Para eso se enfoca en la cohorte que actualmente tiene entre 25 y 35 años y compara la trayectorias educativa y laboral de quienes son primera generación con estudios superiores con la de otros dos grupos: quienes tienen estudios superiores y son hijos de padres profesionales (herederos) y quienes son hijos de padres sin educación superior y tampoco alcanzaron ese nivel de estudios (reproductores). El análisis se basa en la Encuesta de Caracterización Socioeconómica Nacional (Casen) del año 2017 e incluye un conjunto de indicadores sobre el perfil educativo, la actividad laboral, los ingresos y la vivienda. Los resultados muestran que, si bien los estudiantes de primera generación se distancian de los reproductores tanto en términos laborales como socioeconómicos, presentan un conjunto de diferencias con respecto a los herederos, que hacen que este grupo mantenga una distancia tanto en términos educativos como sociales y laborales.
\end{abstract}

PALABRAS CLAVES: GRUPOS GENERACIONALES, TRAYECTORIAS EDUCATIVAS, EMPLEO.

${ }^{1}$ Investigador Centro de Estudios Sociales CIDPA, Valparaíso, Chile. Correo electrónico: felipe@cidpa.cl

${ }^{2}$ Investigador Centro de Estudios Sociales CIDPA, Valparaíso, Chile. Correo electrónico: oscar@cidpa.cl 


\title{
ENSINO SUPERIOR E ESTRUTURA SOCIAL NO CHILE ABORDAGENS DE TRÊS GRUPOS GERACIONAIS
}

\begin{abstract}
RESUMO
Em meados dos anos 2000, a evidência indicava que um em cada sete estudantes do ensino superior no Chile eram a primeira geração de suas famílias em atingir esse nível de ensino. Este artigo tenta explorar as consequências deste processo na condição socioeconômica deste grupo. Para isso, concentra-se na coorte que atualmente tem entre 25 e 35 anos e compara as trajetórias educacionais e laborais daqueles que são a primeira geração com curso superior com a de outros dois grupos: aqueles que têm curso superior e são filhos de pais profissionais (herdeiros) e aqueles que são filhos de pais sem ensino superior e também não atingiram esse nível de ensino (reprodutores). A análise é baseada na Pesquisa Nacional de Caracterização Socioeconômica (Casen) de 2017 e inclui um conjunto de indicadores sobre o perfil educacional, a atividade laboral, a renda e a moradia. Os resultados mostram que, embora os estudantes da primeira geração se distanciem dos reprodutores tanto em termos laborais quanto socioeconômicos, eles apresentam um conjunto de diferenças em relação aos herdeiros que fazem com que esse grupo mantenha uma distância tanto em termos educacionais, quanto sociais e laborais.
\end{abstract}

PALAVRAS-CHAVE: GRUPOS GERACIONAIS, TRAJETÓRIAS EDUCACIONAIS, EMPREGO.

\section{Higher Education AND Social STRUCTURE IN CHILE: APPROACHES FROM THREE GENERATIONAL GROUPS}

\begin{abstract}
In the mid-2000s, evidence showed that one out of seven higher education students in Chile were the first generation in their families to reach this level of education. The present article intends to give insight into the consequences of this process for their socio-economic conditions. For that purpose, it is focused on the currently 25-30 yearold cohort, comparing the educational and labor trajectories of this first generation with higher education to two other groups: those who have higher education and are children of graduated parents (heirs) and those who are children of parents with no higher education, not even reaching that education level (reproducers). The analysis is based on the 2017 National Socio-Economic Characterization Survey (Casen), including a set of indicators about education profiles, labor activity, income and housing. Results show that, regardless of the fact that the first-generation students set apart from reproducers both in labor and social terms, a set of differences between them and the heirs mark social and labor distances.
\end{abstract}

KEYWORDS: GENERATIONAL GROUPS, EDUCATIONAL TRAJECTORIES, EMPLOYMENT. 


\section{INTRODUCCIÓN}

Uno de los procesos importantes ocurridos en las últimas décadas en Chile ha sido el fuerte aumento en el acceso a la educación superior. En poco menos de treinta años, la matrícula prácticamente se ha quintuplicado. De los cerca de 190 mil estudiantes que había en 1984 se pasó a 250 mil en 1990; diez años después, en el 2000, llegaba a cerca de 450 mil, a 620 mil en 2005, 985 mil en 2010 hasta llegar a un millón 120 mil en $2019^{3}$. Pero quizás lo más relevante es que buena parte de este aumento ha estado empujado por el ingreso de sectores hasta hace poco excluidos de este nivel de formación. A mediados de la década pasada se calculaba que cerca del setenta por ciento de los jóvenes que entraban a estudiar una carrera de educación superior provenían de familias en las cuales ninguno de sus miembros había tenido esa oportunidad (Armanet, 2005). La tendencia fue una marca de época. Que siete de cada diez estudiantes de educación superior eran primera generación con estudios superiores de sus familias se convirtió en un tópico que resumía el impacto de las políticas de ampliación en la cobertura escolar y venía a condensar las aspiraciones y estrategias adoptadas por las nuevas generaciones de sectores sin educación superior (CIDE, 2012).

Emergía, así, un nuevo sujeto, el «estudiante de primera generación», reconocido pronto como «caso tipo» de la expansión de la enseñanza superior en Chile. Su presencia ha abierto un campo de investigación incipiente que en otras latitudes existe hace ya varias décadas, sobre todo en el área anglosajona y europeo-occidental. Estos trabajos han mostrado que este tipo de estudiantes suelen provenir de familias con ingresos familiares por debajo del promedio de sus respectivos países, que muchos pertenecen a minorías étnicas - hispanos, negros - y suelen ser más mujeres que hombres (Terenzini, Springer, Yaeger, Pascarella y Nora, 1996; Nuñez y Cuccaro-Alamin, 1998; Lohfink y Paulsen, 2005). Cuando se comparan sus trayectorias educativas con las de quienes son hijos de padres con educación terciaria, resulta que los estudiantes de primera generación suelen ingresar más tarde a la educación superior y hacerlo a programas conducentes a grados académicos inferiores a los que consiguen los «estudiantes tradicionales» (sic) (Pascarella, Pierson, Wolniak y Terenzini,

3 Datos obtenidos desde registros del Sistema de Estadísticas de Educación Superior (SIES) disponibles en https://www.mifuturo.cl/informes-de-matricula/, y desde informes estadísticos del Consejo Nacional de Educación Superior (CNED), descargables desde: https://www.cned.cl/indices-educacion-superior 
2004; Esprivalo y Scott, 2003; Chen, 2005; Mehta, Newbold y O'Rourke, 2011; Soria y Stebleton, 2012).

El objetivo de estos estudios suele ser detectar factores que incidan en el rendimiento y la permanencia de los estudiantes de primera generación en la educación superior para proponer, desde ahí, medidas remediales. Algunos de estos factores se arrastran desde etapas previas a la educación terciaria. El menor capital cultural de sus familias, la falta de preparación en la escuela secundaria o el desconocimiento sobre la dinámica interna de las instituciones de educación superior son algunos de los factores comunes a los estudiantes de primera generación que afectan sus resultados y su integración al sistema $(\mathrm{Nu}-$ ñez y Cuccaro-Alamin, 1998; Choy, 2001). Otros se producen una vez dentro, en el curso mismo de los estudios: los estudiantes de primera generación suelen vincularse menos con la vida universitaria, toman menos cursos extracurriculares y pasan menos tiempo en los establecimientos que los «estudiantes tradicionales», todos factores que terminan afectando el rendimiento, alargando los años de estudio o desembocando en mayores tasas de deserción (Choy, 2001; Collier y Morgan, 2008; Cataldi, Bennett y Chen, 2018). Influye también el hecho de que muchos estudiantes de primera generación trabajan, a veces a tiempo completo, y presentan mayores cargas de responsabilidad familiar. De ahí el calificativo de población de riesgo por parte de algunos investigadores, un término con el que buscan subrayar la necesidad de medidas especiales para retenerlos y evitar su deserción, sobre todo en los dos primeros años de estudios, los dos más críticos para este tipo de estudiantes (Terenzini et al., 1996; Warburton, Bugarin y Nuñez, 2001; Chen, 2005); pues pasado ese punto, lo más probable es que logren nivelar los déficits y obtengan resultados similares a los de quienes venían con un mayor background cultural (Pike y Kuh, 2005). Ahí la importancia que algunos estudios le atribuyen a la motivación con la carrera y sus contenidos, dos dimensiones cruciales para la continuidad, tanto o más que las esperanzas de movilidad depositadas en la obtención de un título profesional (Prospero y Vohra-Gupta, 2007).

Otra línea de investigación en estos países trabaja desde el relato de los estudiantes de primera generación ${ }^{4}$. Uno de los temas que destacan es el dislocamiento posicional que acarrea el hecho de convertirse en graduados (London, 1989, 1992; Orbe, 2007; Davis, 2010; Lowery-Hart y Pacheco, 2011). Quiérase

4 Una buena colección de estudios en esta línea se puede encontrar en Hicks, Butler y Myrick (2019). 
o no, el acceso a estudios superiores rompe con los itinerarios trazados para el común de su clase y eso produce fisuras en la identidad, sobre todo en quienes pertenecen a minorías étnicas y lingüísticas o ingresan a instituciones de alta selectividad. El otro tema surge de los procesos decisionales, cuyos resultados cuestionan, de algún modo, las premisas más deterministas de la teoría de la reproducción. Es cierto, sostienen, que los estudiantes de primera generación provienen de hogares con menos capital económico, cultural y social; pero su relato demuestra que, al contrario de lo que en teoría se asume, los padres han sido un factor clave para las aspiraciones de sus hijos (Gofen, 2009; Hodge y Melin, 2010). Es lo que resume la noción de capital familiar, distinto al económico y al cultural, y del que los estudiantes de primera generación tendrían en abundancia (Gofen, 2009).

Por esta línea de investigación ha transitado parte importante de los estudios desarrollados en Chile en el período más reciente. Algunos han trabajado con los relatos de estudiantes de distinto tipo y regiones para reconstruir el proceso vivido por estudiantes de primera generación desde antes de ingresar a la universidad hasta pasado un tiempo después de egresados (Flannagan, 2017; Ramos, 2018). Los resultados muestran que el ingreso a la educación superior por parte de quienes son primera generación en su familia es un proceso que se alimenta desde etapas tempranas de la vida, donde los padres son fundamentales como estímulo y apoyo, sin cuyo sacrificio sería imposible haber dado este paso, y que supone una cadena de decisiones que a veces tienen que ser frías, instrumentales, elegir, por ejemplo, una universidad de menor prestigio o calidad, todo para cumplir el anhelo de alcanzar un título profesional (Ramos, 2018). Gracias a este paso han logrado una inflexión en la historia de sus familias que es, a la vez, un cambio en su estatus personal - se nota en el trato de los otros, en cierta distancia que se toma con respecto a los pares de antaño (Soto, 2016)_, aunque no siempre se corresponde con un cambio en las condiciones laborales y económicas, sobre todo en zonas marcadas por la ruralidad y una matriz productiva agrícola. A esto se suma que muchos carecen, también, de redes de contacto, y así sus trayectorias terminan siendo más bien horizontales, sin movilidad vertical (Concha, 2009).

Paralela a esta línea de investigación de corte cualitativo se viene desarrollando otra que toma como referente a los estudiantes de primera generación para describir, por su intermedio, la estructura de fondo del sistema educacional vigente en Chile. Jarpa y Rodríguez (2015) comparan las trayectorias educativas de estudiantes de primera generación con las de estudiantes continuistas - 
segunda generación o más de profesionales-, y descubren una serie de diferencias producidas desde la etapa escolar hasta el proceso de selección, admisión y acceso al sistema universitario. De partida, la mayor parte de los estudiantes de primera generación proviene de establecimientos educacionales con financiamiento público, mientras entre los continuistas predominan alumnos de colegios privados. Aunque con rendimientos escolares similares, los puntajes en la Prueba de Selección Universitaria (PSU) no fueron igual de parejos, y eso repercute en diferencias en los procesos de admisión, selección y matrícula que se expresan tanto en los porcentajes de éxito como en diferencias cualitativas relativas al tipo de institución y carrera (Jarpa y Rodríguez, 2015) ${ }^{5}$. Eso solo considerando los datos del sistema formal de admisión a las universidades, porque si se agregan universidades privadas e institutos profesionales que no exigen PSU, las diferencias aumentan. De hecho, sostienen, es justamente este tipo de instituciones donde se concentra la matrícula de estudiantes de primera generación.

Diferencias del mismo orden se encuentran en el estudio de Víctor Orellana (2011) sobre los nuevos profesionales en Chile. Utilizando un conjunto de datos cuantitativos disponibles en registros del Ministerio de Educación, universidades y otras fuentes secundarias, el autor hace una completa radiografía que revela los efectos segmentadores producidos por el sistema de educación superior mismo. Si se consideran los distintos tipos de instituciones que lo conforman, con centros de formación técnica e institutos profesionales y un sistema universitario en que coexisten entidades públicas y privadas de distinto tamaño y nivel de complejidad, aparece un sistema institucional y socialmente segmentado que reproduce las diferencias que existen en la sociedad en su conjunto. La evidencia indica que gran parte de los nuevos profesionales procedentes de los estratos socioeconómicos medios y bajos ha entrado a institutos técnicoprofesionales y universidades no selectivas y estrictamente docentes, mientras que las universidades más complejas y selectivas, en general, permanecen como reducto de los sectores que son segunda o tercera generación con estudios de este tipo. Esto resulta clave, toda vez que para acceder a los puestos más altos

5 Dos de cada cinco estudiantes de primera generación ingresan a carreras de baja selectividad y apenas $2,8 \%$ entra a carreras altamente selectivas, bastante por debajo del $10,5 \%$ de los continuistas en este tipo de carreras. El grado de selectividad lo miden de acuerdo a la distribución de los puntajes. Para que una carrera sea calificada como de alta selectividad, al menos el 50\% de la matrícula debe tener puntajes por sobre los 700 puntos en la Prueba de Selección Universitaria (PSU) (Jarpa y Rodríguez, 2015). 
en la estructura ocupacional es requisito insalvable haber pasado por una universidad selectiva, que son, en el fondo, un mecanismo más para filtrar el acceso a las posiciones económica y socialmente privilegiadas (Orellana, 2011). Ahí lo relevante del estudio de Orellana, que señala los límites del discurso meritocrático enarbolado por los promotores de la privatización de la educación superior y confirma el efecto reproductor del sistema en su conjunto. Pero quizás lo más relevante de este trabajo sean las preguntas que desarrolla en la discusión final. Este estudio es un intento por analizar la estructura social que emerge con el avance del neoliberalismo y de una economía y sociedad de tipo postindustrial y, en este marco, la pregunta que se plantea es ver hasta qué punto y en qué sentido la formación de nuevos profesionales reconfigura la estructura social, tanto en términos económicos como socio-demográficos e ideológicos.

Plantear el problema en esos términos nos parece relevante y su investigación puede ser ampliada observando el fenómeno desde aristas complementarias a lo avanzado hasta aquí. Todos los estudios citados abordan el fenómeno desde los estudiantes de primera generación propiamente tales (Concha, 2009; Soto, 2016; Ramos, 2018) o considerando al conjunto de la población estudiantil (Jara y Rodríguez, 2015; Orellana, 2011).

En nuestro caso, la propuesta es avanzar esta vez desde una perspectiva comparada que considere a los distintos grupos que se forman con el acceso de nuevos sectores a la educación superior. Esto, por lo siguiente: si la estructura social es un espacio de posiciones generadas por la posesión de recursos de distinto tipo, y si esas posiciones solo se comprenden en relación con el conjunto, entonces la reconfiguración de tal espacio tendría que ser observada contrastando a los distintos grupos que genera el proceso mismo. Es lo que hicieron los autores Castillo y Cabezas (2010) cuando contrastaban a los estudiantes de «primera generación» con dos grupos de la misma cohorte: los «reproductores» — también hijos de padres sin estudios superiores pero que, a diferencia de los «primera generación», no siguieron estudiando-, y con los «herederos» estudiantes de educación superior hijos de técnicos y profesionales_ ${ }^{6}$. El estu-

6 Los términos «reproductores» y «herederos» son tomados de las teorías de la reproducción elaborada por Bourdieu y Passeron $(1996,2003)$. La tesis central es que el sistema escolar constituye un mecanismo que reproduce la distribución de las distintas formas de capital entre los grupos, reproduciendo con ello la posición de las distintas clases en la estructura de una sociedad. Herederos, en este caso, alude a los grupos que heredan altos niveles de capital escolar, mientras que con el término Reproductores se hace referencia los grupos que reproducen la posición de los grupos con niveles históricamente bajos de capital cultural. 
dio describe la trayectoria educacional de cada uno de estos grupos y busca factores que pudieran explicar las diferencias en sus respectivos trayectos. Descubren, así, la importancia de las estrategias desplegadas durante la educación secundaria, de la claridad de objetivos al momento de egresar de cuarto medio y de la preparación para la Prueba de Selección Universitaria (PSU) como factores para ingresar y luego no desertar de la educación superior (Castillo y Cabezas, 2010). El punto, sin embargo, es que este estudio se centra en la etapa estudiantil, sin que se sepa qué pasa con estos grupos después, cuando terminan sus estudios. Orellana (2011) hace una aproximación al respecto, pero con datos agregados a nivel de población general en los que se pierde el componente generacional del proceso. Por lo tanto, no sabemos bien todavía en qué se diferencian las trayectorias ocupacionales de los actuales estudiantes de primera generación si se las compara con las de quienes no ingresaron a la educación superior, pero son, como ellos, hijos de padres y madres sin estudios superiores («reproductores»), y en qué se asemejan o difieren respecto a las de quienes tienen igualmente estudios superiores, pero son hijos de padres con educación superior («herederos»).

En lo que sigue intentamos cubrir estas cuestiones extendiendo el estudio hacia esta etapa, cuando concluyen los estudios superiores y se empiezan a definir las posiciones de cada cual en la estructura socioocupacional. Veremos en qué ocupaciones específicas se están posicionando los egresados de primera generación y hasta qué punto su distribución ocupacional se acerca a la de los herederos y se distancia de los empleos en que se insertan quienes no lograron estudiar una carrera técnica o profesional — que siguen siendo, después de todo, más de la mitad de las generaciones jóvenes actuales-. Aspectos como el tipo de actividad en que se desempeñan, las características de su relación laboral o de la situación contractual, son parte de las variables con las que se irá observando las proximidades y distancias entre estos grupos. Veremos, también, si estas trayectorias educativo-laborales se corresponden con condiciones sociales y económicas diferenciadas, si la situación de quienes estudiaron por primera vez en sus familias se separa de la que presentan sus pares de origen (reproductores) y se empareja con la de quienes provienen de familias profesionales (herederos) tanto en términos de los ingresos laborales como de otras condiciones materiales de existencia - acceso a bienes de consumo durable (vivienda, automóvil, por ejemplo)_. Nos parece que esa comparación descriptiva de la trayectoria educativa, laboral, económica de jóvenes primera generación, reproductores y herederos puede ser un aporte para comprender los cambios en la estructura social que pudiera estar produciendo un proceso social-histórico- 
generacional tan significativo como el de la masificación de la educación superior en Chile.

\section{Metodología}

Para abordar estas cuestiones, optamos por una estrategia basada en el análisis de fuentes secundarias de datos cuantitativos. Utilizaremos la Encuesta de Caracterización Socioeconómica Nacional (Casen) del año 2017.

La principal limitante de la encuesta Casen es que la pregunta por la escolaridad del padre se hace solo a la persona que aporta el principal ingreso del hogar. Eso obliga a dejar fuera a todos quienes viven con sus padres y a quienes son pareja del proveedor principal. Con eso, el tamaño de la muestra efectiva sufre una merma. Como contrapartida, el hecho de que sean los proveedores quienes responden, permite centrarse en quienes ya han asumido su independencia económica, cuestión no menor si lo que se pretende es explorar la situación laboral y económica vinculada a la actividad de quienes pertenecen a la cohorte y no a la actividad de sus padres.

Teniendo en cuenta este último punto, decidimos concentrarnos en la cohorte de 25 a 35 años. Tomar como referencia a esta cohorte permite cubrir relativamente bien el componente generacional de la expansión en el acceso a la educación superior ocurrido en las últimas décadas. Quienes tenían 35 años en 2017, egresaron de la enseñanza media 17 años antes, el año 2000, justo cuando se producía la inflexión más fuerte en los niveles de matrícula de educación superior y comenzaba el ingreso ya más masivo de jóvenes provenientes de los quintiles con más bajos ingresos. Además, es a partir de los 25 años que se produce un descenso fuerte en la cantidad de estudiantes y aumentan la inserción laboral y la independencia residencial, por lo que usar como límite inferior esa edad permitirá informar sobre ocupaciones e ingresos imputables a los casos que pertenecen a los grupos de interés para este estudio.

El primer paso fue generar estos tres grupos. Serán primera generación los titulados de educación superior hijos de padres sin estudios superiores; reproductores quienes no hayan seguido estudios superiores y sean hijos de padres sin estudios de educación superior; y herederos quienes tengan estudios 
superiores y sean hijos de padres con ese mismo nivel de estudios ${ }^{7}$. De cada grupo se extraerá información relativa a empleo, ingresos, vivienda, hogar, situación económica y otras variables de caracterización general, tratando siempre de comparar la situación de mujeres y hombres y de dos rangos etarios quinquenales: de 25 a 29 y de 30 a 35 años —esto último para distinguir entre quienes vienen recién egresando y quienes egresaron hace más tiempo- Para cada uno de estos grupos se realizaron los mismos análisis ${ }^{8}$. Estos describen los niveles de estudio, la condición de actividad, el oficio, la categoría ocupacional, los niveles de ingreso y pobreza, y algunos aspectos del hogar y la vivienda de los jefes de hogar de esta cohorte.

\section{Resultados}

\subsection{HEREDEROS, REPRODUCTORES Y PRIMERA}

\section{GENERACIÓN}

Los jefes de hogar concentran al 30\% de la cohorte de 25 a 35 años. Seis de cada diez son hombres; el otro $40 \%$ son mujeres. Eso le imprime un sesgo de género al conjunto que habrá que tener en cuenta. De los grupos que se forman al cruzar la escolaridad del jefe de hogar con la del padre, el más numeroso es el de los reproductores $(40,1 \%)$; le siguen los primera generación con estudios superiores $(34,9 \%)$ y después los herederos $(20,9 \%)$. Ninguno de estos grupos presenta diferencias importantes asociadas al género. Tanto hombres como mujeres tienen porcentajes que ajustan a esta distribución. Lo que sí parece importante es el factor geográfico. Los tres grupos son principalmente urbanos —eso por los altos índices de urbanización en Chile-, pero la mayor parte de los rurales son reproductores, cuestión que contrasta con el perfil claramente urbano de los primera generación y, sobre todo, de los herederos.

7 Utilizamos la escolaridad del padre solo como referencia. La encuesta informa también sobre la escolaridad de la madre; ambos tienden a coincidir.

8 Los procesamientos incluyen análisis bivariados simples mediante tablas de contingencia y análisis de varianza para comparar los promedios de ingresos. Todos los procesamientos fueron realizados mediante el software para análisis estadístico SPSS. 


\section{GRÁFICO 1. GRUPOS GENERACIONALES SEGÚN ZONA DE RESIDENCIA (\%)}

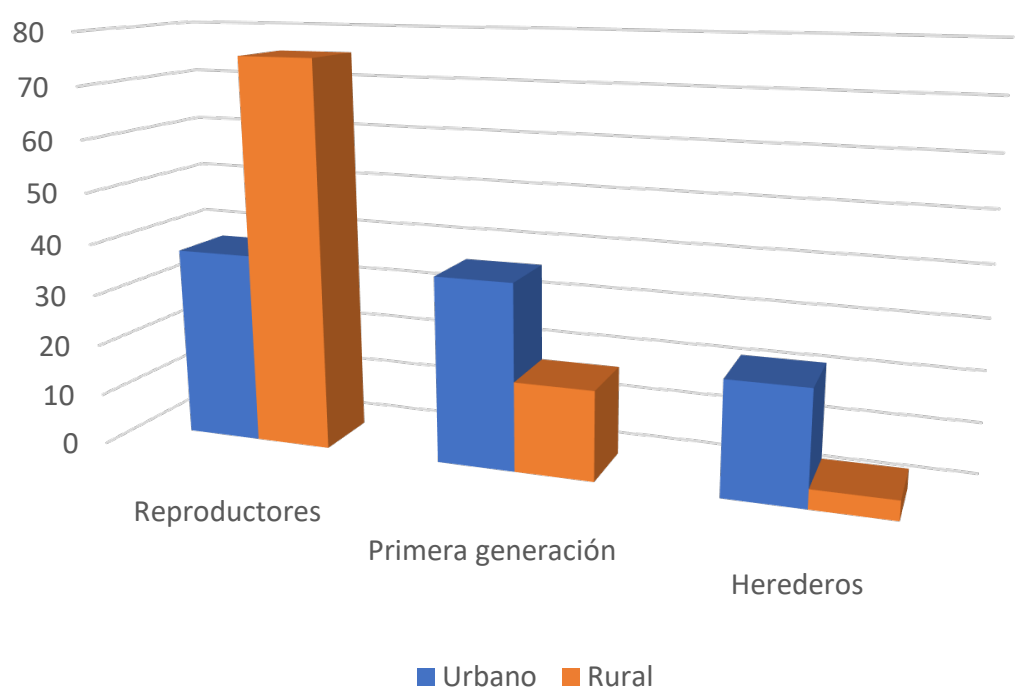

Fuente: Elaboración propia sobre la base de Casen 2017.

\subsection{TRAYECTORIAS EDUCACIONALES}

La mayor parte de los reproductores alcanzó la educación media — 70\% completa y $16 \%$ incompleta-, y alrededor de un 12\% solo llegó hasta sexto, séptimo u octavo año de enseñanza básica. La razón más importante para haber dejado sus estudios hasta ahí fue el trabajo. Otra razón de peso fue dedicarse a los quehaceres del hogar y a la crianza de hijos. La primera aparece claramente asociada a los hombres; las dos segundas, a las mujeres.

Herederos y estudiantes de primera generación comparten el hecho de haber terminado la enseñanza secundaria y pasado a la educación superior. Ese es su rasgo constitutivo. Sus perfiles educativos, sin embargo, presentan algunas diferencias a tener en cuenta. Una tiene que ver con el tipo de estudios superiores. Si bien ambos grupos están compuestos, en su mayoría, por universitarios, el porcentaje de este tipo de estudiantes entre los herederos supera largamente a los universitarios de primera generación. La diferencia es cercana al $12 \%$ en el pregrado y al $9 \%$ en los estudios de postgrado. Lo contrario ocurre con los estudios técnicos, que entre los primera generación duplican y más el porcentaje que alcanzan entre los herederos.

\section{GRÁFICO 2. TIPO DE ESTUDIOS SUPERIORES SEGÚN GRUPO GENERACIONAL (\%)}




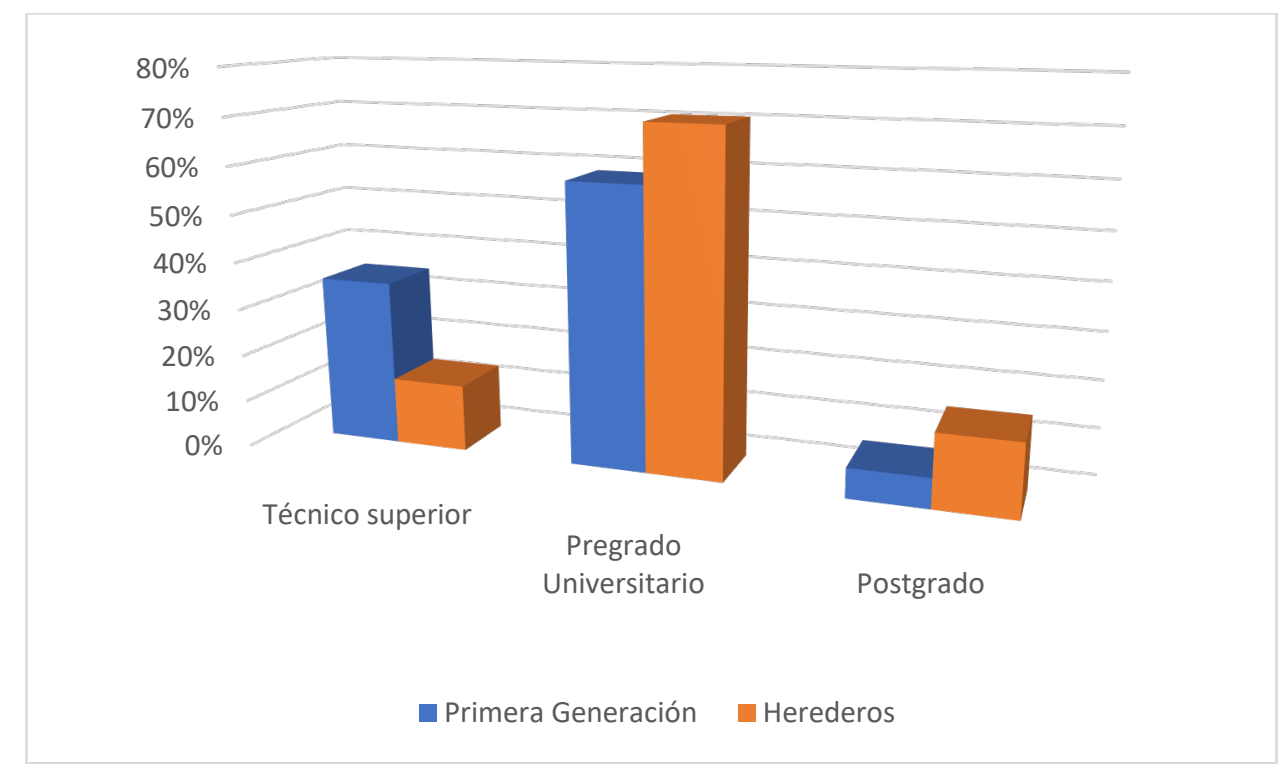

Fuente: Elaboración propia sobre la base de Casen 2017.

Esto implica una diferencia correlativa en el tipo de instituciones en que cursaron estudios. Centros de formación e institutos profesionales, sobre todo estos últimos, tienen un peso mucho mayor entre los primera generación que entre los herederos. Para los primera generación, los institutos profesionales constituyen, de hecho, el tipo de establecimiento más frecuente. En las universidades, en cambio, hay más herederos que primera generación, y eso en todas sus modalidades y tipos, aunque las diferencias son significativas en las universidades privadas que pertenecen al Consejo de Rectores y en las universidades extranjeras. 
GRÁFICO 3. INSTITUCIONES DE EDUCACIÓN SUPERIOR SEGÚN GRUPO GENERACIONAL (\%)

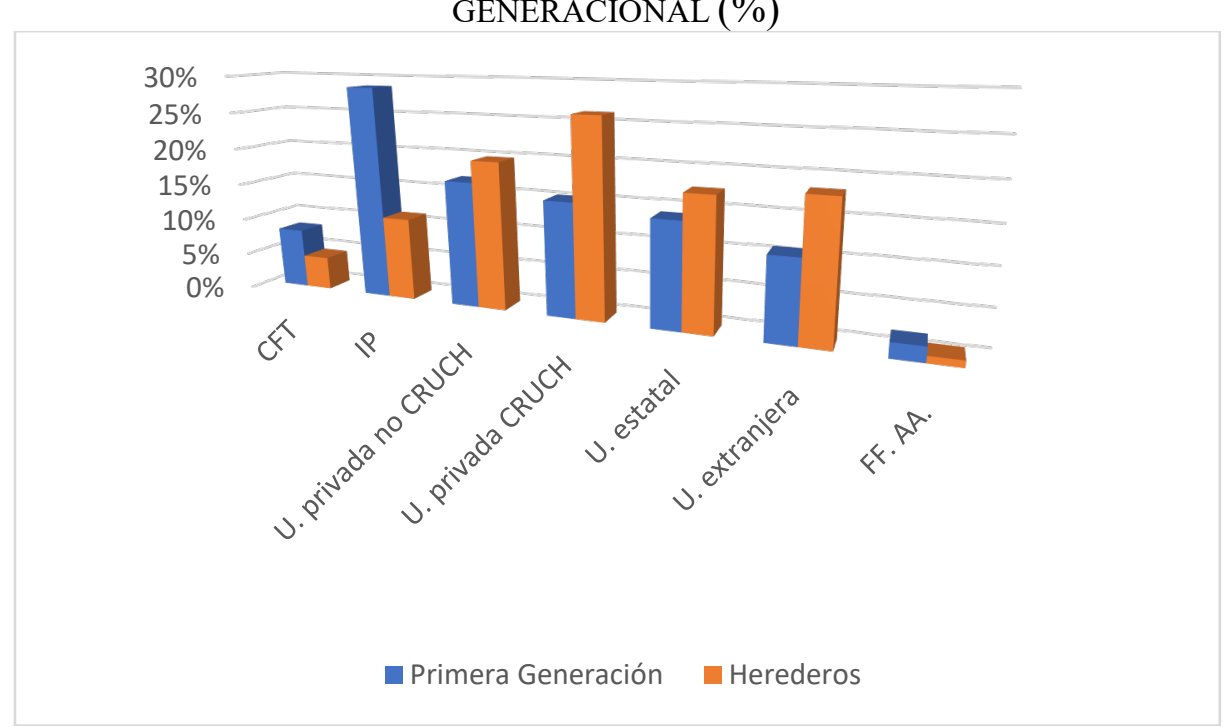

Fuente: Elaboración propia sobre la base de Casen 2017.

A estas diferencias horizontales relacionadas con el tipo de estudios superiores y las instituciones se agregan otras relativas al área de estudios y al perfil de carreras más comunes en uno y otro grupo. Si bien ambos comparten una estructura relativamente similar en la distribución de las distintas áreas de estudio, con la ingeniería-industria-construcción, la administración, la salud y la educación como las más destacadas, el peso de estas áreas respecto al total de cada grupo presenta algunas diferencias importantes. Todas las carreras que entran en el campo de la ingeniería, la industria y la construcción gravitan más entre los herederos que entre los primera generación. Lo mismo ocurre con las ciencias sociales-periodismo y las artes-humanidades. En cambio, los estudios vinculados a las tecnologías de la información, los servicios y, sobre todo, la educación, tienen más peso entre los primera generación que entre los herederos. 


\section{GRÁFICO 4. ÁREA DE ESTUDIO SEGÚN GRUPO GENERACIONAL (\%)}

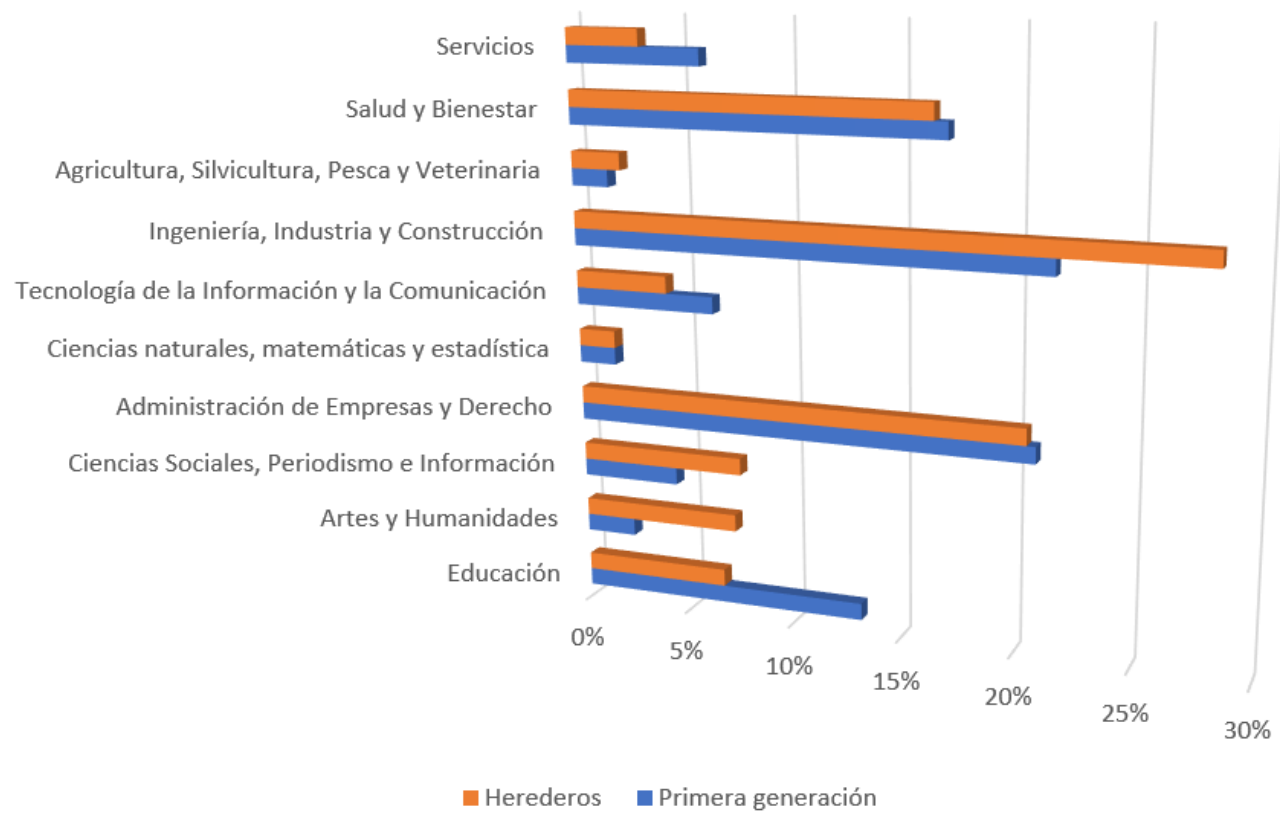

Fuente: Elaboración propia sobre la base de Casen 2017.

Por último, pero no menos importante, están las diferencias dentro de cada ámbito o área de estudios relativos a las carreras específicas que cursaron. No deja de ser relevante que carreras como Ingeniería Comercial, por ejemplo, sean igualmente importantes tanto para primera generación como para herederos. O que una carrera como Derecho se cuente entre las diez más importantes en ambos grupos. Hay, todavía, una diferencia de grado, con un porcentaje que sigue siendo mayor entre los herederos que entre los primera generación, sin embargo, no es tan marcada como en Medicina, por ejemplo, que figura entre las diez carreras más frecuentes entre los herederos $-4,1 \%$ de los casos-, pero no de los primera generación. Por cierto que hay médicos de primera generación, pero su presencia en carreras del área salud se concentra más bien en la enfermería y otras especialidades técnicas, que son, de hecho, de las carreras más frecuentes para los y, sobre todo, las estudiantes de primera generación. Algo parecido ocurre en el ámbito de la ingeniería, donde existe una amplia gama de técnicos e ingenieros en ejecución de distintas especialidades que proceden sobre todo de los segmentos de primera generación, al tiempo que carreras como la Ingeniería Civil o Industrial tienen un peso específico mucho mayor entre los herederos. 
TABLA 1. DIEZ CARRERAS MÁS FRECUENTES SEGÚN GRUPO GENERACIONAL

\begin{tabular}{|l|r|r|}
\hline \multicolumn{2}{|c|}{ Carrera } & \multicolumn{2}{c|}{ Carrera } & \multicolumn{1}{c|}{ Primera generación } \\
\hline Ingeniería Civil & 5,8 Técnico en Enfermería & 2,7 \\
\hline Derecho & $4,8 \begin{array}{l}\text { Licenciatura en Enferme- } \\
\text { ría }\end{array}$ & 2,3 \\
\hline Medicina & 4,1 Ingeniería Comercial & 2,1 \\
\hline Ingeniería Comercial & 3,4 Psicología & 2,1 \\
\hline Ingeniería Civil Industrial & 3,0 Administración de Em- \\
presas & 2,0 \\
\hline Periodismo & 2,8 Derecho & 2,0 \\
\hline Psicología & 2,5 Enfermería & 1,9 \\
\hline Arquitectura & 2,4 Educación Parvularia & 1,8 \\
\hline Enfermería & 2,3 Ingeniería Informática & 1,8 \\
\hline Publicidad & 2,3 Contador Auditor & \\
\hline
\end{tabular}

Fuente: Elaboración propia sobre la base de Casen 2017.

\subsection{SitUACIÓN LABORAL}

Corresponde ver, entonces, si esto se traduce o no en diferencias laborales. Para eso se describe una serie de variables que van desde las condiciones laborales hasta los oficios en que se desempeñan.

\section{a) Actividad y condiciones laborales}

Lo primero es señalar que la mayor parte de los casos en los tres grupos se encuentra laboralmente activo. Tanto entre los herederos como entre los primera generación, los ocupados superan el $91 \%$. Solamente los reproductores presentan niveles de desocupación e inactividad más altos $-4,7 \%$ y $11,4 \%$, respectivamente-, y esto fundamentalmente por la alta inactividad de las mujeres: más del $25 \%$ de las mujeres de este grupo se encuentra inactiva y otro $6,4 \%$ está desocupada. La principal razón para su inactividad son los quehaceres del hogar y la crianza de hijos; entre herederas y primera generación, en cambio, la inactividad es por estudios. Eso marca una diferencia importante primero respecto a los hombres de su mismo estrato, en su mayoría ocupados y a tiempo completo (94\%), y luego respecto a las mujeres herederas y primera 
generación, cuyas tasas de ocupación son considerablemente más altas y próximas a las que presentan los hombres de sus respectivos grupos.

GRÁFICO 5. CONDICIÓN DE ACTIVIDAD SEGÚN GRUPO GENERACIONAL POR SEXO $(\%)$

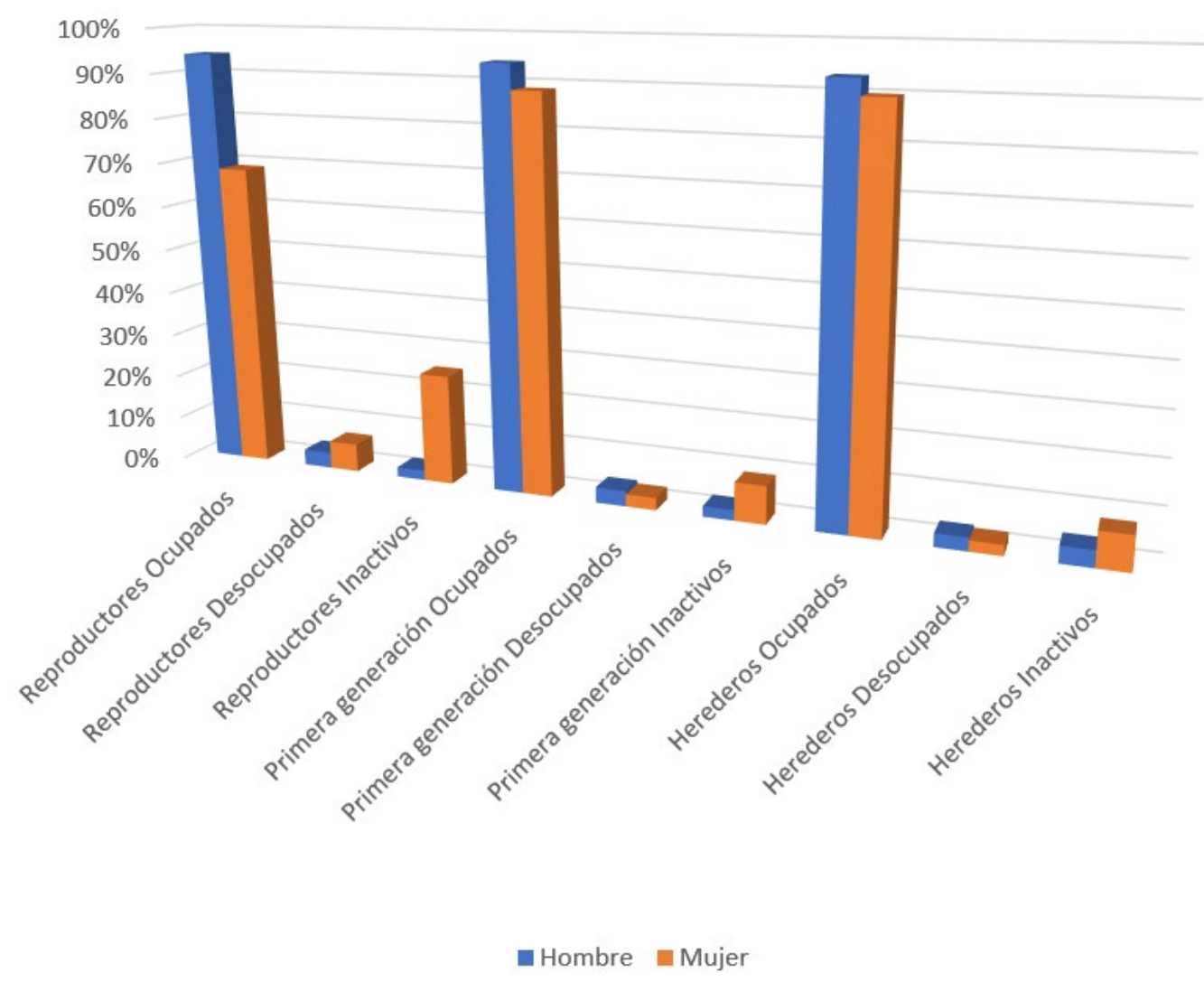

Fuente: Elaboración propia sobre la base de Casen 2017.

Entre quienes sí trabajan, la mayoría lo hace en empleos permanentes y a jornada completa. Cuentan, además, con contrato. En su mayoría, el contrato es a plazo indefinido y lo acordaron en trato directo con la empresa, sin subcontratista $u$ otro agente intermediario. Por lo tanto, en líneas generales, lo que predomina en todos los grupos son condiciones laborales bastante parecidas, con porcentajes de contratación y una distribución de jornadas similares en los tres grupos. En todas las variables hay, no obstante, un margen de diferencia que revela la mayor concentración de casos con precariedad laboral entre los reproductores. Se da en los niveles de contratación, el empleo temporal, los contratos 
a plazo fijo y la subcontratación. Se observa, también, en la jornada prolongada, que entre los reproductores llega al 6,7\%. Además, los reproductores son el único grupo en que las condiciones se mantienen e incluso algunas se precarizan al pasar de los 25-29 a los 30-35 años, como en los empleos temporales y eventuales, por ejemplo, que suben al pasar de un tramo etario a otro. Y lo interesante, a nuestros efectos, es la posición intermedia que adoptan los estudiantes de primera generación respecto a los otros dos grupos. Ocurre con el empleo temporal, por ejemplo, o con el contrato fijo y la subcontratación, en que los niveles de precariedad no son tan negativos como entre los reproductores, pero tampoco tan ventajosos como entre los herederos.

TABLA 2. CONDICIONES LABORALES SEGÚN GRUPO GENERACIONAL (\%)

\begin{tabular}{|c|l|c|c|c|}
\hline \multicolumn{2}{|c|}{ Condiciones laborales } & Reproductores & $\begin{array}{c}\text { Primera } \\
\text { generación }\end{array}$ & \\
\hline \multirow{3}{*}{ Temporalidad } & Permanente & 78,2 & 86,9 & 93,0 \\
\cline { 2 - 5 } & Temporal & 21,8 & 13,1 & 7,0 \\
\hline \multirow{3}{*}{ Jornada } & Completa & 85,0 & 84,2 & 85,3 \\
\cline { 2 - 5 } & Parcial & 6,7 & 9,2 & 9,1 \\
\cline { 2 - 5 } & Prolongada & 6,4 & 4,9 & 4,1 \\
\hline \multirow{3}{*}{ Contrno } & Diurno & 77,0 & 79,6 & 81,4 \\
\cline { 2 - 5 } & Nocturno & 2,6 & 5,3 & 2,7 \\
\cline { 2 - 5 } & Rotativo & 19,7 & 14,3 & 15,1 \\
\hline \multirow{2}{*}{ Plazo contrato } & Sí & 84,10 & 92,45 & 90,47 \\
\cline { 2 - 5 } & No & 16,90 & 7,55 & 9,53 \\
\hline \multirow{2}{*}{ Trato } & Indefinido & 70,7 & 76,4 & 80,4 \\
\cline { 2 - 5 } & Fijo & 86,7 & 23,5 & 19,6 \\
\cline { 2 - 5 } & Directo & 13,0 & 90,3 & 95,6 \\
\hline \multirow{2}{*}{ Subcontratista } & & 9,7 & 4,40 \\
\hline
\end{tabular}

Fuente: Elaboración propia sobre la base de Casen 2017.

\section{b) Perfil de actividad: categoría ocupacional y oficios}

Respecto al tipo de empleo en que se desempeñan, un elemento común a los tres grupos es el peso del sector privado en la ocupación. Tanto quienes forman parte de la primera generación como los herederos y reproductores son, en su mayoría, empleados u obreros de empresas privadas. En eso coinciden los tres grupos. Las diferencias están en la magnitud que alcanzan el sector público y el empleo por cuenta propia. El empleo por cuenta propia es relevante entre 
los reproductores: $19,5 \%$ de los jefes de hogar de este segmento trabaja por su cuenta, casi el doble que el $11,6 \%$ de los herederos y que el 10,5\% de los primera generación. En el sector público, en cambio, primera generación y herederos presentan niveles comparativamente altos, sobre todo los primera generación, que encontrarían en organismos del gobierno central y municipal o en empresas del sector público una fuente de empleo importante. De hecho, entre ambos grupos cubren buena parte de los empleados del sector público de la cohorte. Para los reproductores, en cambio, si bien no deja de ser un espacio laboral importante $-5,9 \%$ - no llega al nivel de los otros dos grupos.

\section{GRÁFICO 6. CATEGORÍA OCUPACIONAL SEGÚN GRUPO GENERACIONAL (\%)}

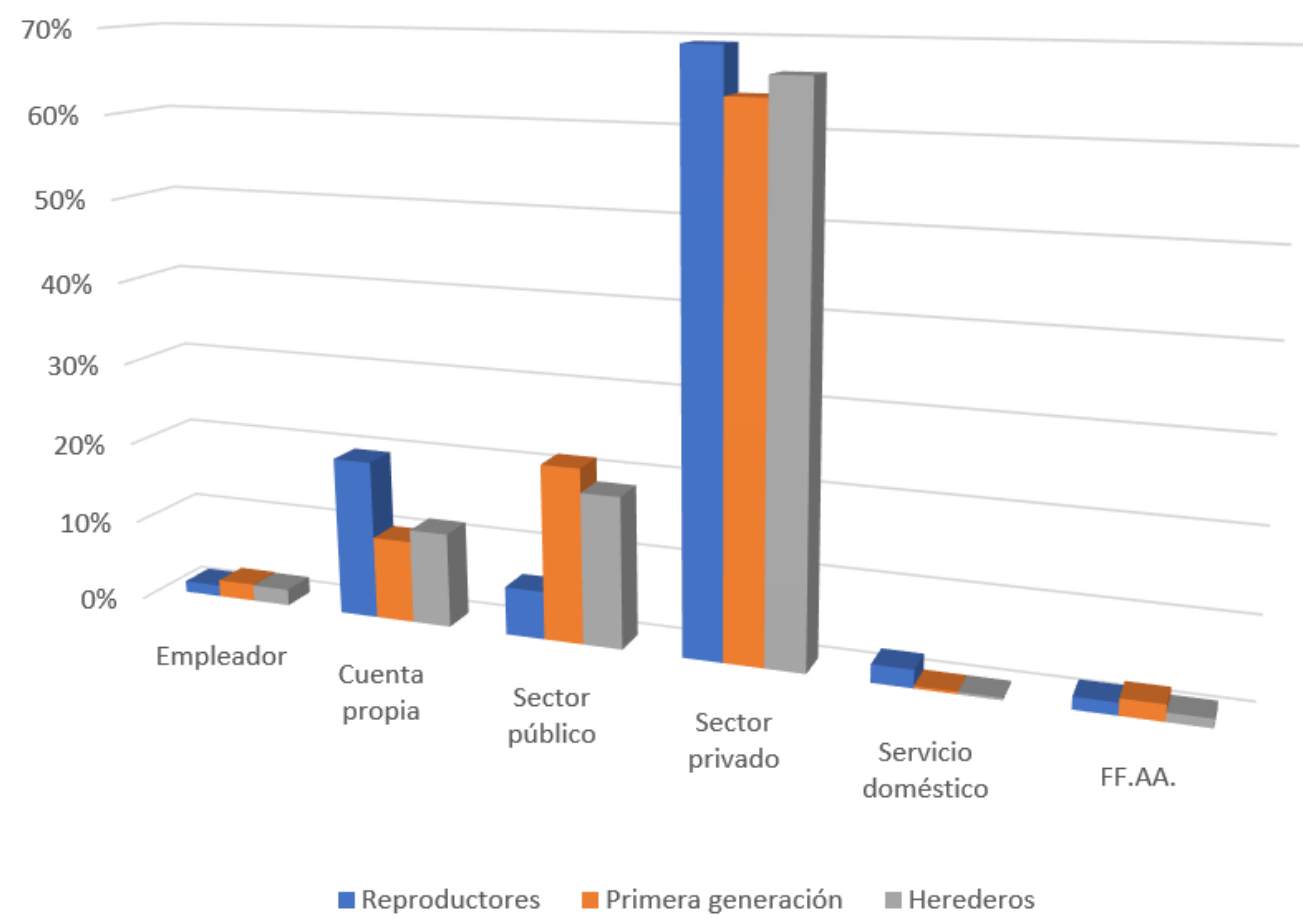

Fuente: Elaboración propia sobre la base de Casen 2017.

Ordenado en ramas de actividad, lo que se observa es que, en líneas generales, las actividades inmobiliarias y empresariales absorben la mayor cantidad de fuerza de trabajo. Esto se da en los tres grupos, pero sobre todo en reproductores y herederos. Los primera generación también participan de esta rama, poco más de un tercio se dedica a actividades inmobiliarias y empresariales, pero lo más importante para este grupo son los servicios sociales y de salud. Este es, en cierto modo, un sector-nicho para los primera generación, donde han encontrado espacio enfermeros y otros especialistas y técnicos de la salud 
que constituyen un segmento importante de los egresados de este grupo. Eso les diferencia de los reproductores, cuya participación en este tipo de servicios es marginal si se compara con las actividades de la agroganadería —un sector más bien marginal para los primera generación -, las ligadas al transporte, los hoteles y restaurantes, la construcción y el sector empresarial. Y lo mismo ocurre con los herederos, cuya participación en los servicios sociales y de salud no dejan de ser importantes — concentran al 15,9\% de los casos-, aunque no alcanzan, de todos modos, el peso que para este grupo tienen las actividades empresariales y la construcción.

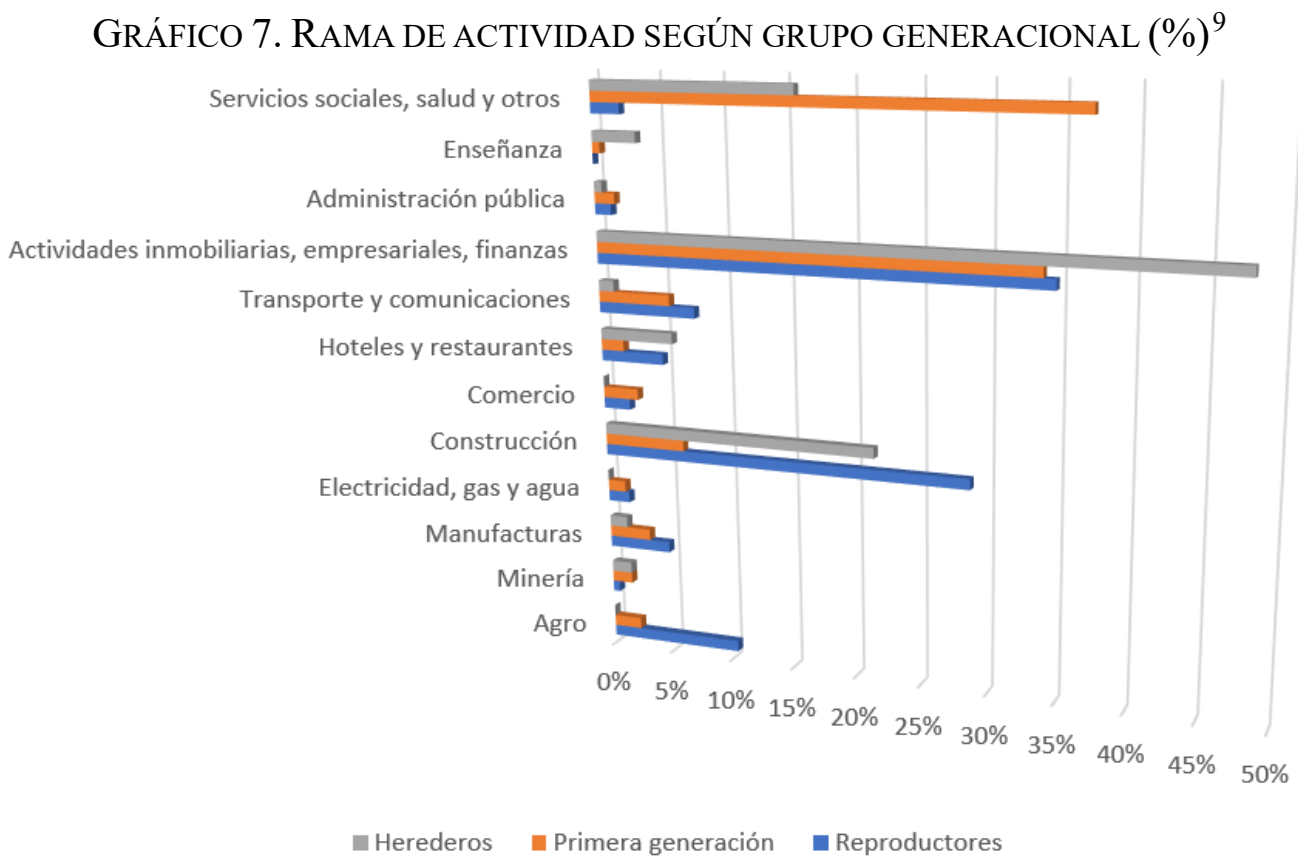

Fuente: Elaboración propia sobre la base de Casen 2017.

Ahora bien. Si se revisa la larga lista de oficios que contiene la encuesta, lo primero que llama la atención es que reproductores y reproductoras figuran en una variedad amplia de oficios, muchos de los cuales son celdas vacías entre los primera generación y, sobre todo, entre los herederos. A grandes rasgos, destaca el trabajo como vendedores del comercio establecido y de quioscos, sobre todo en el caso de las reproductoras, para quienes este es el oficio más

9 Para mayor simplicidad en esta tabla se juntaron las categorías actividades inmobiliarias, empresariales y finanzas debido al escaso porcentaje que registraban estas últimas. Y la de servicios sociales y de salud con otros servicios comunitarios. 
frecuente $-9,5 \%$ son vendedoras del comercio y $6 \%$, de quioscos-, seguido de cerca por el servicio doméstico (9\%), la cocina en restaurantes, el aseo de hoteles y oficinas y el trabajo agrícola no calificado (6\%), el de cajeras $(4,9 \%)$, o secretarias $(3,8 \%)$. Y entre los hombres reproductores, además del comercio, hay un número importante de camioneros, conductores de taxis y colectivos, mecánicos, carpinteros, mozos de labranza y peones agropecuarios, peones de carga, cocineros, reponedores de inventario, operarios de distintos tipos de maquinarias, porteros y guardias, y diversos oficios ligados a la construcción, incluyendo a carpinteros, perqueteros, peones de construcción, electricistas, soldadores. 
TABLA 3. DIEZ PRINCIPALES OFICIOS SEGÚN GRUPO GENERACIONAL

\begin{tabular}{|c|c|c|c|c|c|}
\hline \multicolumn{2}{|c|}{ Reproductores } & \multicolumn{2}{|c|}{ Primera generación } & \multicolumn{2}{|c|}{ Herederos } \\
\hline Oficios & $\%$ & Oficios & $\%$ & Oficios & $\%$ \\
\hline $\begin{array}{l}\text { Vendedores } \\
\text { de tiendas y } \\
\text { almacenes }\end{array}$ & 6,8 & $\begin{array}{l}\text { Vendedores } \\
\text { tiendas }\end{array}$ & 4,5 & $\begin{array}{l}\text { Especialistas } \\
\text { organización } \\
\text { y } \\
\text { administració } \\
\mathrm{n} \text { de } \\
\text { empresas }\end{array}$ & 7,0 \\
\hline $\begin{array}{l}\text { Peones } \\
\text { agropecuario } \\
\mathrm{s}\end{array}$ & 5,7 & $\begin{array}{l}\text { Maestros } \\
\text { primaria }\end{array}$ & 3,4 & $\begin{array}{l}\text { Inspectores } \\
\text { de seguridad } \\
\text { y salud y } \\
\text { control de } \\
\text { calidad }\end{array}$ & 5,7 \\
\hline $\begin{array}{l}\text { Conductores } \\
\text { camiones }\end{array}$ & 3,9 & $\begin{array}{l}\text { Ayudantes de } \\
\text { enfermería }\end{array}$ & 3,0 & Médicos & 4,9 \\
\hline Cocineros & 3,9 & $\begin{array}{l}\text { Personal } \\
\text { enfermería } \\
\text { nivel medio }\end{array}$ & 2,4 & Abogados & 4,1 \\
\hline $\begin{array}{l}\text { Vendedores } \\
\text { de quioscos y } \\
\text { mercado }\end{array}$ & 3,7 & Contadores & 2,3 & $\begin{array}{l}\text { Autores, } \\
\text { periodistas }\end{array}$ & 2,8 \\
\hline $\begin{array}{l}\text { Peones de } \\
\text { carga }\end{array}$ & 3,5 & $\begin{array}{l}\text { Profesores } \\
\text { enseñanza } \\
\text { superior }\end{array}$ & 2,3 & $\begin{array}{l}\text { Ingenieros } \\
\text { civiles }\end{array}$ & 2,8 \\
\hline $\begin{array}{l}\text { Personal } \\
\text { doméstico }\end{array}$ & 3,2 & $\begin{array}{l}\text { Profesionales } \\
\text { nivel medio } \\
\text { administrativ } \\
\text { os }\end{array}$ & 2,3 & $\begin{array}{l}\text { Arquitectos y } \\
\text { afines }\end{array}$ & 2,8 \\
\hline Carpinteros & 2,8 & $\begin{array}{l}\text { Especialistas } \\
\text { organización } \\
\text { y } \\
\text { administració } \\
\text { n de } \\
\text { empresas }\end{array}$ & 2,2 & $\begin{array}{l}\text { Analistas } \\
\text { informáticos }\end{array}$ & 2,4 \\
\hline $\begin{array}{l}\text { Porteros, } \\
\text { guardianes }\end{array}$ & 2,8 & $\begin{array}{l}\text { Analistas } \\
\text { informáticos }\end{array}$ & 2,2 & $\begin{array}{l}\text { Vendedores } \\
\text { tiendas y } \\
\text { almacenes }\end{array}$ & 2,3 \\
\hline $\begin{array}{l}\text { Limpiadores } \\
\text { de oficinas y } \\
\text { otros }\end{array}$ & 2,7 & $\begin{array}{l}\text { Profesores } \\
\text { secundaria }\end{array}$ & 2,1 & $\begin{array}{l}\text { Programador } \\
\text { es } \\
\text { informáticos }\end{array}$ & 2,3 \\
\hline
\end{tabular}

Fuente: Elaboración propia sobre la base de Casen 2017.

Muchos de estos oficios no existen entre los herederos y primera generación. No hay herederos que sean peones del agro y de la construcción o que se dediquen de lleno a la pesca. Sí hay vendedores, camareros y otros oficios de este tipo, pero son porcentajes menores y parecieran empleos más bien tempo- 
rales en su biografía, que dejan cuando ya pasan de los 30 años o completan su ciclo formativo y se afirman en la profesión que estudiaron. Los oficios más comunes entre los herederos son todos oficios que requieren calificación. Entre los hombres destacan los especialistas organizacionales de empresas, controles de calidad, analistas informáticos, arquitectos, abogados, ingenieros de todas las áreas, sobre todo civiles y comerciales, un porcentaje importante de médicos, psicólogos y programadores informáticos. Y entre las mujeres, destacan médicos, abogadas, periodistas, la pedagogía en sus distintos niveles y especialidades, enfermeras de nivel superior, especialistas organizacionales, arquitectas, decoradoras, contadoras, ingenieras civiles, programadoras informáticas, un margen de filósofas, sociólogas, historiadoras, además de cultoras de diferentes artes y artesanías, que son oficios que no existen o son muy marginales entre las reproductoras.

Todos estos son oficios que también encontramos entre los primera generación, aunque en menor porcentaje. En algunos coinciden, como es el caso de enfermeros y maestros de educación. Pero en otros hay más distancias. Sucede con los abogados, por ejemplo, oficio importante entre los herederos, pero que agrupa al 1,1\% de los primera generación; o con los médicos, que llegan al $4,9 \%$ de los herederos y solo al $0,6 \%$ de los primera generación. La diferencia, en ese sentido, no es tanto por la inexistencia de este tipo de profesiones como por la magnitud que alcanzan en uno y otro grupo. De hecho, el oficio más frecuente entre los primera generación no pertenece al ámbito técnico o profesional; es el de vendedores del comercio, como en los reproductores. Después vienen oficios que requieren especialización, como el de enfermeras y enfermeros, maestros de enseñanza, profesionales y técnicos de la salud o el de especialistas en organizaciones empresariales y contadores. Además, si se observa el listado completo, más allá de los diez oficios más comunes, se encuentra que los primera generación también trabajan en una serie de oficios técnicos y operarios en que no hay herederos, algo que les da una amplitud y diversidad de oficios que no tiene este último grupo y que acerca a los estudiantes de primera generación a los reproductores.

Resumido esto en tipos de oficios más sintéticos, destaca, en primer lugar, que en varios de ellos los reproductores superan por amplio margen a los primera generación y los herederos. Particularmente marcada es la diferencia en los empleos no calificados, en las labores de operarios y artesanos, y de operadores de maquinaria. También se da en los servicios de ventas y del comercio, ocupaciones habituales para reproductores, y sobre todo, reproductoras, y tam- 
bién para los primera generación. Esta es, de hecho, la categoría ocupacional que más aproxima a los primera generación con los reproductores y que a la vez los distancia de los herederos. Y lo mismo se da también en los empleos de oficina y en las categorías de oficiales, operarios y artesanos, aunque no tan acentuado como en el rubro de las ventas.

En otras categorías ocupacionales la situación es la inversa. Se da en los poderes ejecutivo y legislativo, donde los primera generación se acercan a los herederos y permanecen a distancia de los reproductores, pero sobre todo en dos categorías que vienen a ser la extensión de los niveles de formación: en la de profesionales y científicos, donde no hay reproductores y se concentra la mayor parte de los primera generación, aunque no al nivel de los herederos; y en los oficios técnicos de nivel medio, una categoría compuesta básicamente por primera generación y herederos, más por los primeros que por los segundos.

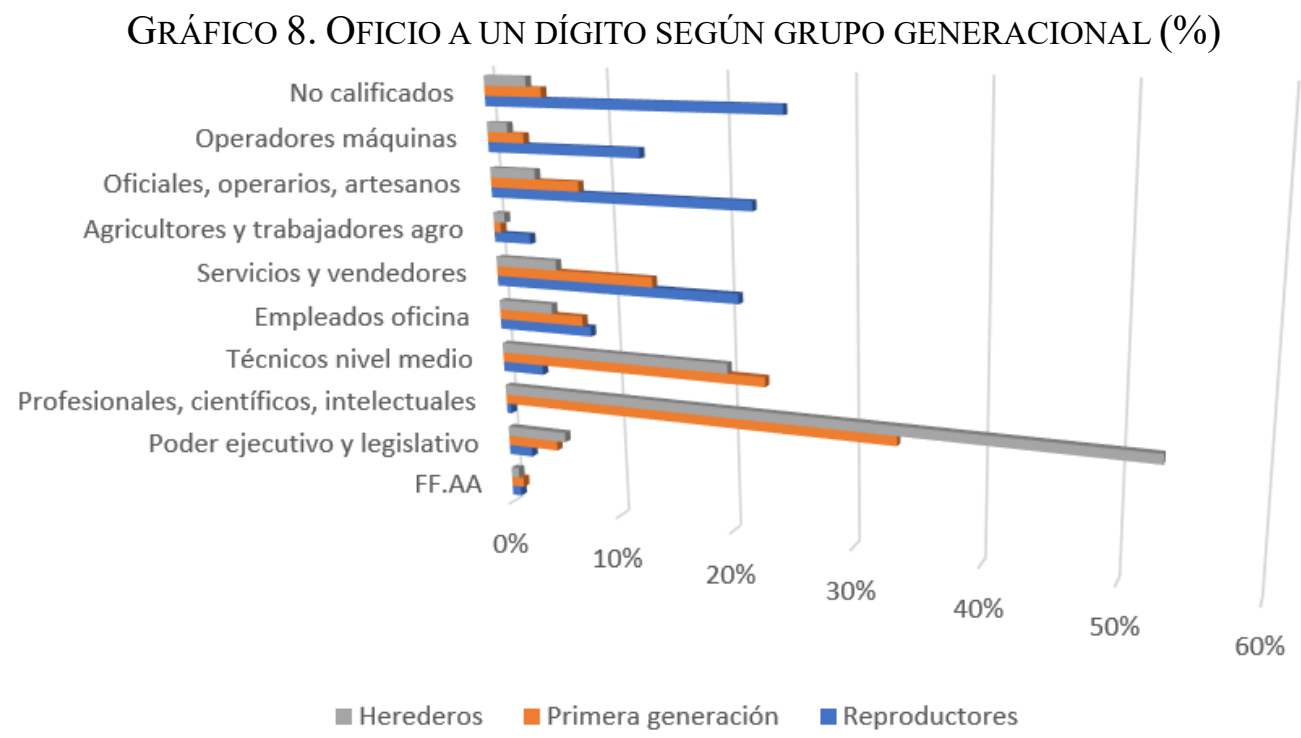

Fuente: Elaboración propia sobre la base de Casen 2017.

Aparece así una fuerza de trabajo segmentada cuya estructura ocupacional tiende a coincidir con los grupos generacionales construidos para este análisis. En efecto, que haya actividades como las inmobiliarias y empresariales en que los tres grupos presentan alta participación, o un rubro como la construcción, que absorbe a parte importante de los herederos y reproductores, no im- 
plica necesariamente que las posiciones dentro de cada rama de actividad sean también coincidentes. Puede que miembros de los tres grupos coincidan en un mismo sector de actividad, pero lo hacen ocupando posiciones distintas dentro de la organización del trabajo. La construcción es, en este sentido, un buen ejemplo: tanto herederos como reproductores están insertos en este rubro, unos como arquitectos, ingenieros, administradores $\mathrm{u}$ otros cargos de «trabajo intelectual», y los otros como peones, soldadores, carpinteros u otros oficios de «trabajo físico». Y algo similar se produce en el área de la salud, donde han encontrado espacio enfermeros y otros especialistas y técnicos que constituyen una fracción importante de los egresados de primera generación y que conviven con un eslabón médico compuesto, en su gran mayoría, por hijos e hijas de padres ya profesionales.

Se aprecia, de este modo, una posición dual de los primera generación que ya se perfila como una de las características que define a este grupo. Por un lado, se distancian de los reproductores, con oficios técnicos y profesionales que no existen en este grupo, aunque solo parcialmente, sobre todo por la magnitud que conserva el trabajo en las ventas y el comercio. Y, por el otro lado, al convertirse en técnicos y profesionales de diversas áreas, se aproximan a los herederos, pero sin alcanzar - todavía - los niveles que presenta este grupo en algunas profesiones hasta ahora reservadas a las élites.

\section{TRAYECTORIAS Y CONDICIÓN SOCIOECONÓMICA}

Para ver cómo se expresan estos trayectos educativo-laborales en la condición socioeconómica, revisamos brevemente lo que sucede con los ingresos, el acceso a bienes durables y la pobreza.

\subsection{INGRESOS}

El análisis de los ingresos se basa en los ingresos del trabajo ${ }^{10}$. Los resultados arrojan diferencias significativas entre los grupos. Quienes presentan el

10Nos centramos en los ingresos del trabajo y no en los ingresos de la ocupación principal, teniendo en cuenta que hay personas que realizan más de una actividad. Al mismo tiempo, preferimos los ingresos del trabajo a los totales porque lo que nos interesa es ver el efecto de los trayectos socioeducativos sobre la situación laboral, sin 
promedio de ingresos más bajo son los reproductores. Ganan en promedio unos $\$ 420.000$ (unos US\$620, con un salario mínimo legal actual de $\$ 301.000$ ), menos de la mitad que los primera generación y una tercera parte del ingreso promedio de los herederos.

Existen casos de reproductores que alcanzan niveles de ingresos superiores a la media de su grupo, pero el rango de ingresos, en general, es acotado y hay poca diferencia entre el ingreso máximo y el mínimo y un grado de dispersión comparativamente más bajo que entre los primera generación y los herederos (gráfico 9).

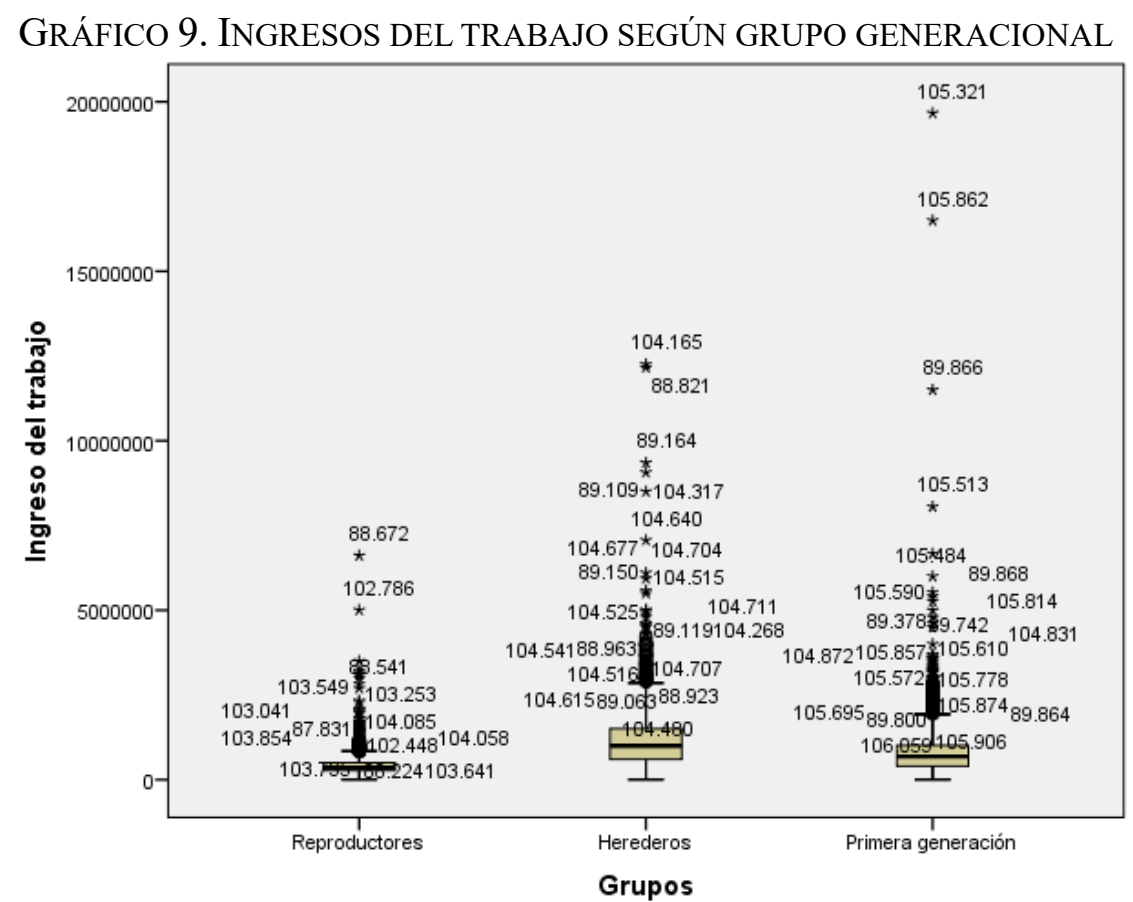

Fuente: Elaboración propia sobre la base de Casen 2017.

Además, mientras en herederos y primera generación hay una diferencia de ingresos importante al pasar del tramo de 25-29 al de 30-35 años, en el caso de los reproductores el incremento es poco significativo y más bien lo que

considerar ingresos recibidos mediante programas de política social, renta de propiedades u otra fuente distinta al trabajo. 
habría en este grupo es la llegada temprana a un techo en los niveles de ingresos.

GRÁFICO 10. INGRESOS DEL TRABAJO EN PESOS PROMEDIO SEGÚN GRUPO GENERACIONAL POR TRAMO ETARIO

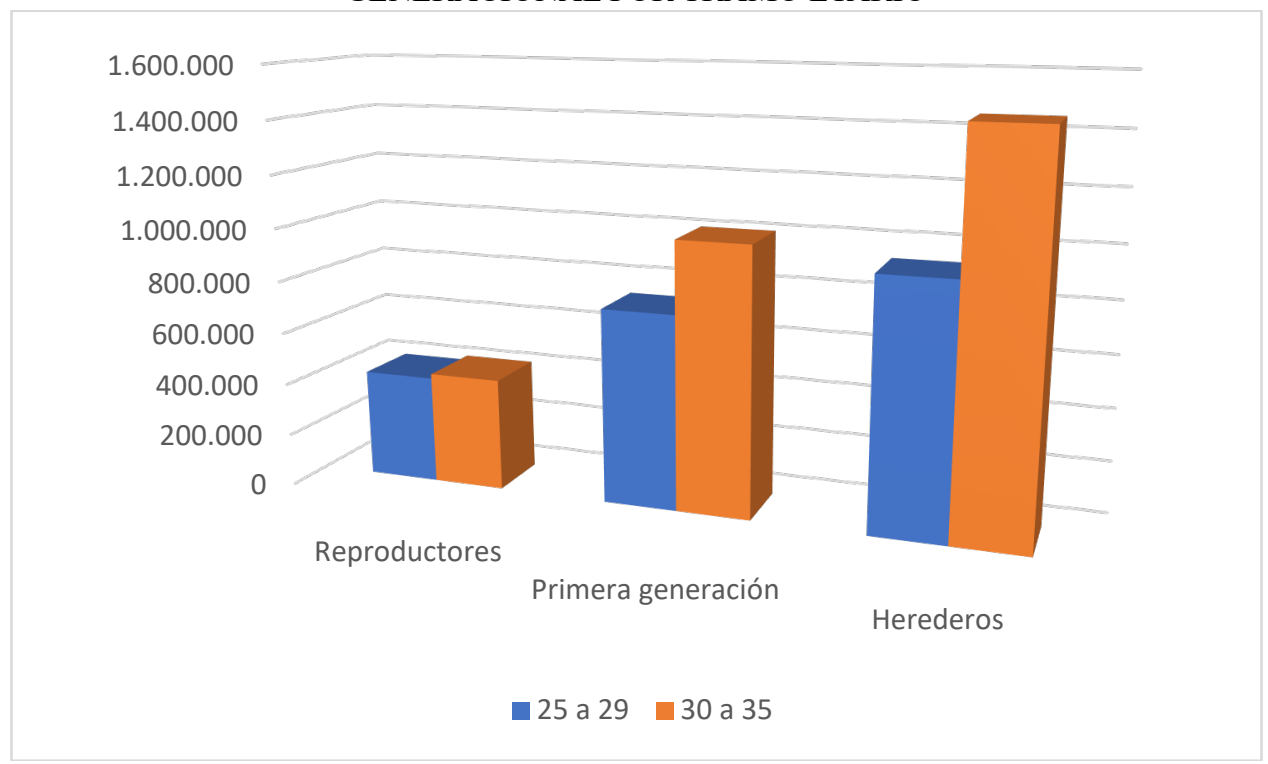

Fuente: Elaboración propia sobre la base de Casen 2017.

Esto se confirma al analizar los deciles de ingresos. Si bien los tres grupos presentan casos en todos los deciles, el modo de distribución es claramente diferente. Los reproductores se concentran en los deciles I al III, tienen también una cantidad importante de casos entre los deciles IV al IX, pero un porcentaje bajo en el de más altos ingresos. El resultado es una curva de pendiente negativa entre el primer y el último decil. La curva de los primera generación y los herederos, en cambio, tiene pendiente positiva, con pocos casos en los primeros deciles, porcentajes que van aumentando conforme se pasa de los de más bajos a los de más altos ingresos y que alcanzan su mayor concentración hacia el final de la curva, entre los deciles VIII al X. Eso diferencia a ambos grupos de los reproductores. A esto se suma el hecho de que en los dos aumenta el porcentaje de casos en los últimos dos deciles cuando se pasa del tramo de 25-29 al de 3035 años, sobre todo en el decil X, cuestión que no se observa e incluso es lo opuesto a lo que pasa con los reproductores. Ahí está la brecha fundamental que se produce con los primera generación, cuya curva y modo de distribución se acercan mucho más a los herederos que a los reproductores. 
Hay, sin embargo, dos puntos en los que estos dos grupos difieren. Uno está en los deciles de ingresos medios y bajos: los primera generación tienen un porcentaje más alto de casos entre los deciles I al VI que los herederos y no baja significativamente al pasar de un tramo etario al otro, como sí ocurre en este último grupo. El otro es que, si bien ambos grupos se concentran en los deciles de más altos ingresos, del VIII al X, el grado de concentración de los herederos en el último decil es evidente, sobre todo en el tramo etario de más edad, llegando al doble y más que el porcentaje de los primera generación en este mismo decil.

TABLA 4. DECIL DE INGRESOS SEGÚN GRUPO GENERACIONAL Y TRAMO ETARIO

$(\%)$

\begin{tabular}{|c|c|c|c|c|c|c|}
\hline \multirow{2}{*}{ Decil } & \multicolumn{2}{|c|}{ Reproductores } & \multicolumn{2}{c|}{ Primera generación } & \multicolumn{2}{c|}{ Herederos } \\
\cline { 2 - 7 } & $25-29$ años & $30-35$ años & $25-29$ años & $30-35$ años & $25-29$ años & 30-35 años \\
\hline I & 10,9 & 14,8 & 5,3 & 1,8 & 1,9 & 0,9 \\
\hline II & 14 & 14 & 3,6 & 3,5 & 1,8 & 0,8 \\
\hline III & 14,7 & 12,7 & 5,1 & 3,8 & 2,7 & 1,7 \\
\hline IV & 11,2 & 11,9 & 6,1 & 5,4 & 1,6 & 2,2 \\
\hline V & 10 & 11 & 6,7 & 6,4 & 6,5 & 2,1 \\
\hline VI & 7,7 & 8,8 & 8 & 8,2 & 3 & 4,1 \\
\hline VII & 11,2 & 9,9 & 7,3 & 9,4 & 7,6 & 4,5 \\
\hline VIII & 8,4 & 9,6 & 16,3 & 16,1 & 11,4 & 6,3 \\
\hline IX & 8,8 & 5,2 & 19,2 & 19 & 19,1 & 20,4 \\
\hline X & 3,1 & 2,2 & 22,2 & 26,4 & 44,4 & 57 \\
\hline
\end{tabular}

Fuente: Elaboración propia sobre la base de Casen 2017.

Resulta, entonces, que la división en reproductores, primera generación y herederos se corresponde con una partición correlativa en los niveles de ingresos laborales. Los primera generación se despegan por arriba de los reproductores y se acercan a los herederos, con casos que incluso superan en su límite máximo al promedio de este último grupo, pero sin llegar al punto de una fusión entre los promedios de ambos grupos. Es lo que informa un análisis posthoc de las medias de ingresos del trabajo, que arroja tres grupos diferenciados según niveles de ingresos. 
TABLA 5. ANÁLISIS POST-HOC SOBRE INGRESOS DEL TRABAJO SEGÚN GRUPO GENERACIONAL

\begin{tabular}{|l|l|c|c|c|c|}
\hline \multirow{2}{*}{ HSD Tukey $^{\mathrm{a}, \mathrm{b}}$} & \multicolumn{1}{|c|}{ Grupos } & $\mathrm{N}$ & \multicolumn{3}{c|}{ Subconjunto para alfa $=0.05$} \\
\cline { 4 - 6 } & & & 1 & 2 & 3 \\
\cline { 4 - 6 } & Reproductores & 219050 & 421850,13 & & \\
\cline { 2 - 6 } & Primera generación & 203436 & & 886523,97 & \\
\cline { 2 - 6 } & Herederos & 121951 & & & 1194086,57 \\
\hline
\end{tabular}

Fuente: Elaboración propia sobre la base de Casen 2017.

\subsection{BIENES DURABLES}

El acceso a bienes durables amplía el registro para el análisis de la situación socioeconómica. Partimos por la vivienda. Aquí abordamos la situación respecto a la propiedad de la vivienda y a sus características materiales.

En relación con la propiedad, destaca el hecho de que el mayor porcentaje de propietarios de viviendas está entre los reproductores y no entre los herederos ni los primera generación. Más del 18\% de los reproductores vive en una vivienda que es propia y ya pagada, bastante por sobre el 10,8\% de primera generación y el 5,4\% de herederos. Probablemente esta diferencia se deba al efecto de una política focalizada que facilita el acceso a vivienda social a los sectores de menores recursos y que traspasa al mercado el acceso a vivienda propia de los otros grupos. Por ahí se explica el bajo porcentaje de primera generación y herederos que son dueños de la vivienda que habitan, sobre todo en el tramo etario más joven. Al pasar de los 30 años la diferencia se acorta, aumenta el porcentaje de primera generación y herederos que están pagando una vivienda propia, pero de todos modos la mayor parte en ambos grupos sigue siendo arrendatario. 
GRÁFICO 11. SITUACIÓN DE PROPIEDAD SEGÚN GRUPO GENERACIONAL POR TRAMO ETARIO $(\%)$

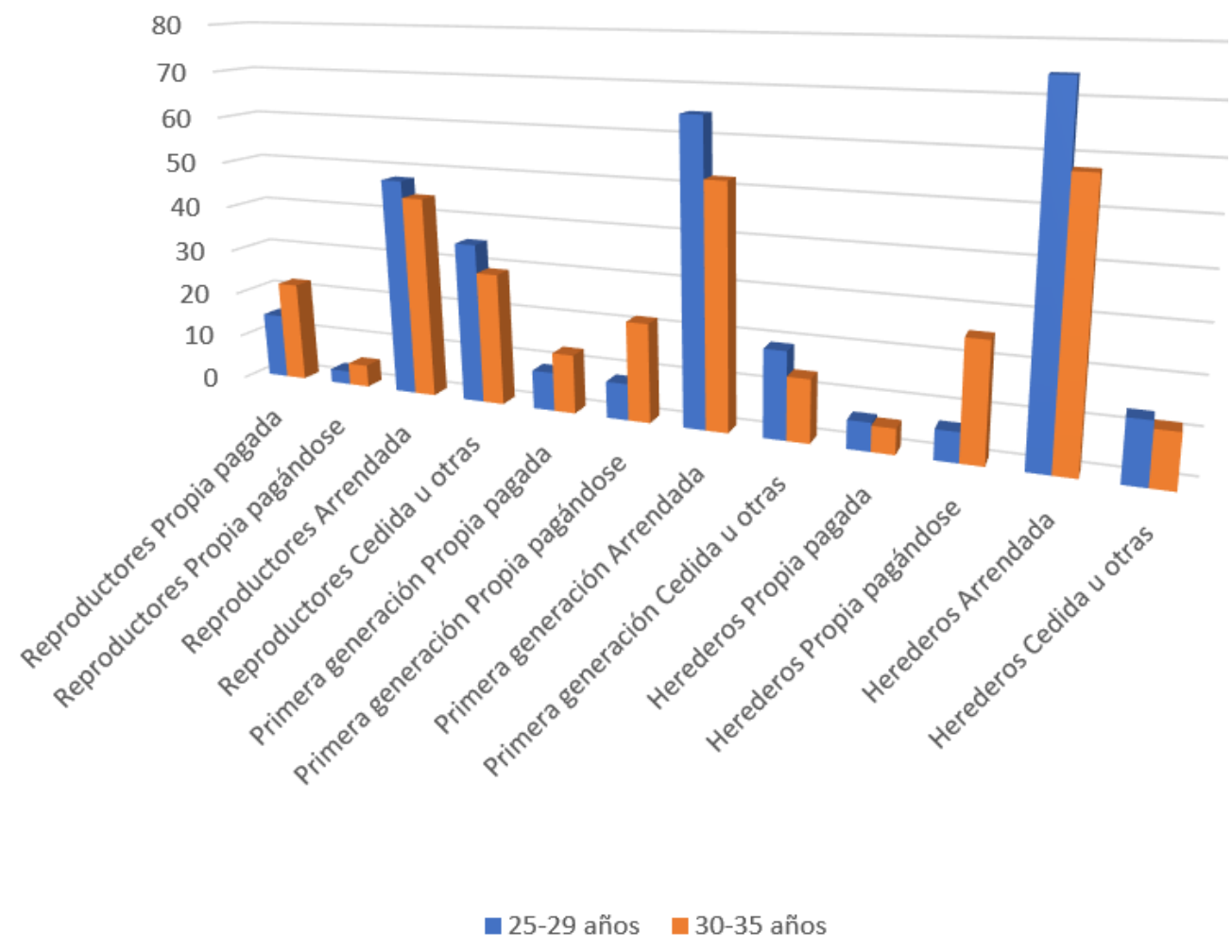

Fuente: Elaboración propia sobre la base de Casen 2017.

Eso respecto a la propiedad. En cuanto al tipo de vivienda, lo primero es que la mayor parte de los casos de todos los grupos habita en casas con muros, pisos y techumbre que están en buenas condiciones. La calidad global de la vivienda es, en su mayoría, aceptable. Y lo mismo pasa con las condiciones de materialidad. Eso no evita, sin embargo, que haya casos cuyas viviendas presentan elementos en mal estado. Los mayores déficit están entre los reproductores. Este es el grupo con mayor porcentaje de casas con pisos, muros y techos en estado aceptable o deficiente. Y lo importante en este punto es que aquí se vuelve a dar aquella situación intermedia de los primera generación. Ocurre con el estado de los muros, en que el porcentaje de viviendas en condiciones aceptables es similar al de los herederos, sin que alcancen, de todos modos, el nivel de este grupo, y manteniendo, por consiguiente, cierta proximidad con los reproductores. Y ocurre lo mismo con el piso, la techumbre y la vivienda en general. 
TABLA 6. CONDICIONES DE MUROS, PISOS Y TECHOS DE VIVIENDA SEGÚN GRUPO GENERACIONAL

\begin{tabular}{|l|l|c|c|c|}
\hline \multirow{3}{*}{ Condición } & Estado & Reproductores & $\begin{array}{c}\text { Primera gene- } \\
\text { ración }\end{array}$ & Herederos \\
\hline \multirow{4}{*}{ Muros } & Bueno & 62,5 & 85,2 & 92,1 \\
\cline { 2 - 5 } & Aceptable & 29,5 & 12,8 & 6,6 \\
\cline { 2 - 5 } & Malo & 8,0 & 1,9 & 1,0 \\
\hline \multirow{3}{*}{ Pisos } & Bueno & 64,6 & 83,7 & 91,0 \\
\cline { 2 - 5 } & Aceptable & 27,2 & 14,1 & 7,4 \\
\cline { 2 - 5 } & Malo & 8,2 & 2,3 & 1,3 \\
\hline \multirow{3}{*}{ Techo } & Bueno & 64,5 & 81,7 & 91,1 \\
\cline { 2 - 5 } & Aceptable & 25,5 & 14,0 & 7,0 \\
\cline { 2 - 5 } & Malo & 9,8 & 4,1 & 1,7 \\
\hline
\end{tabular}

Fuente: Elaboración propia sobre la base de Casen 2017.

Algo parecido pasa con los materiales de la vivienda. Mientras los herederos se concentran en viviendas con exteriores de hormigón armado, los reproductores habitan construcciones de cemento, ladrillo, madera o tabique, todos tipos de construcción poco frecuentes entre los herederos. Y en medio, de nuevo, los primera generación: como los herederos, el principal material de los muros es el hormigón armado; pero como en los reproductores, hay un porcentaje relativamente alto de casos cuyas viviendas están hechas con materiales de albañilería o tabiquería.

\section{GRÁFICO 12. MATERIALES DE VIVIENDA SEGÚN GRUPO GENERACIONAL (\%)}

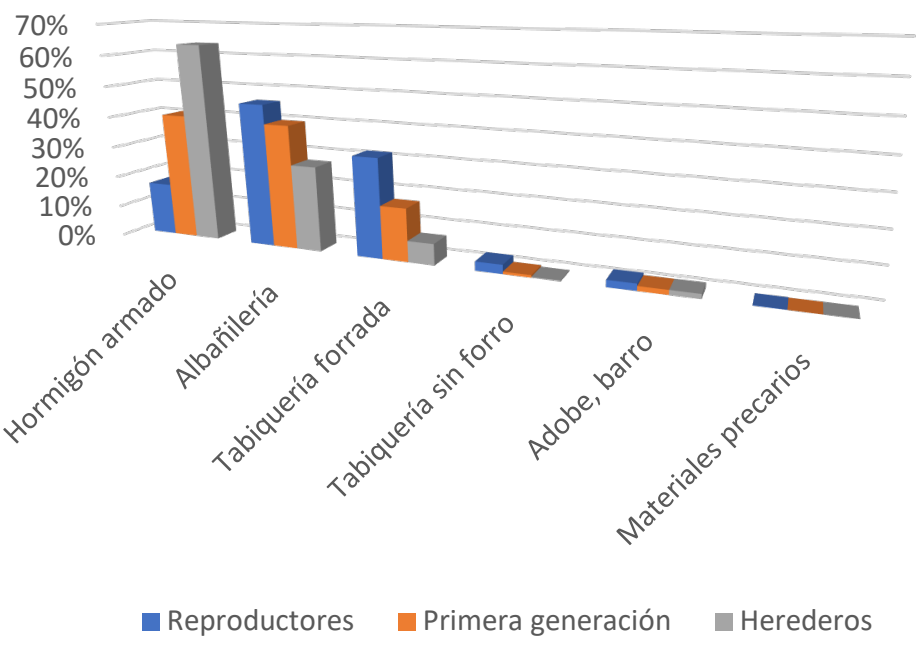

Fuente: Elaboración propia sobre la base de Casen 2017. 
Esto se corresponde, a su vez, con el modo en que se distribuyen los tipos de vivienda en los diferentes grupos. Los primera generación y los reproductores coinciden en que ambos grupos presentan un porcentaje comparativamente alto de casos que habitan viviendas aisladas y casas pareadas por uno o por los dos lados. Todos estos son tipos de vivienda poco frecuentes entre los herederos. De hecho, lo que destaca de este grupo es la cantidad de casos que viven en departamentos con ascensor. Más de la mitad de los herederos habita viviendas de este tipo, haciendo de ellos una suerte de «habitante tipo» de las edificaciones que trajo el boom inmobiliario de las últimas décadas, torres de nueva generación que se diferencian de los bloques de edificios con cuatro pisos máximo, tan característicos de la vivienda fiscal de los años sesenta, por ejemplo, o de la vivienda social de los años noventa y dos mil.

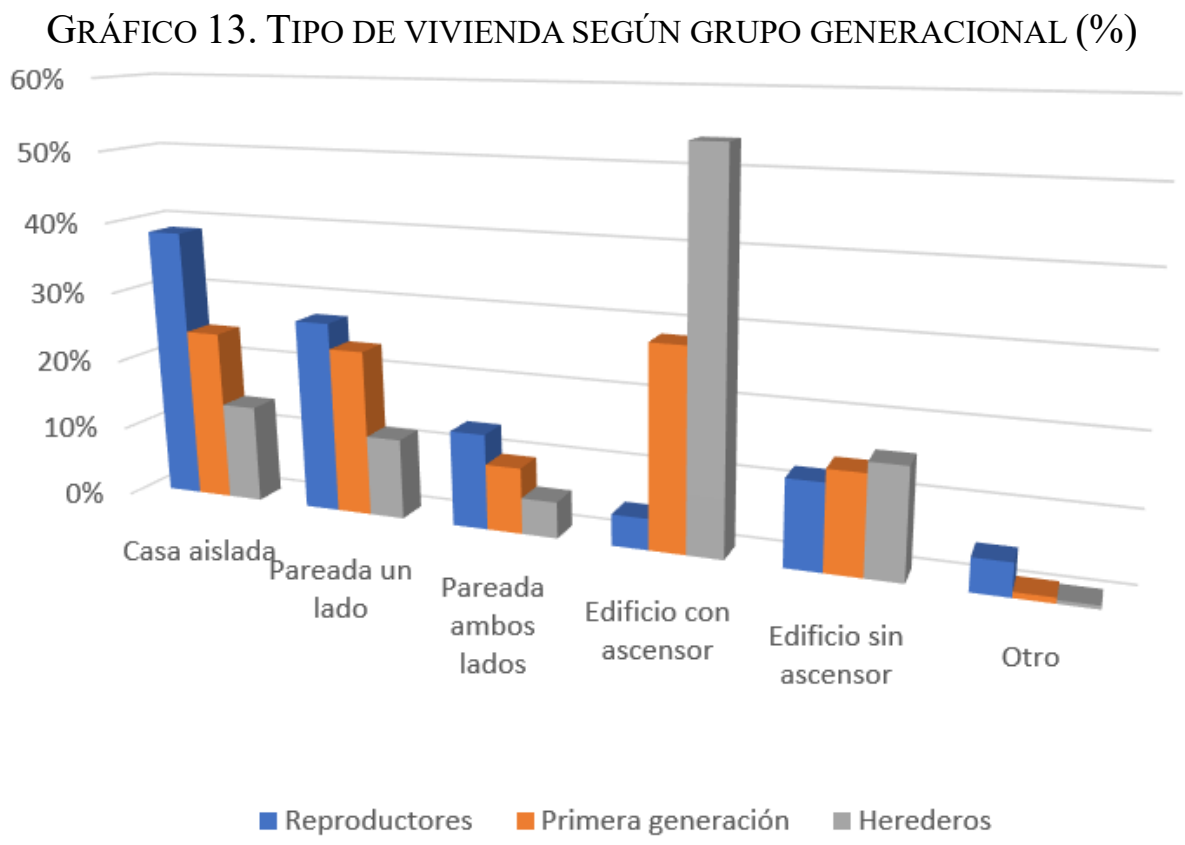

Fuente: Elaboración propia sobre la base de Casen 2017.

Hay otras características de los hogares en que la dualidad de los primera generación también aparece, aunque se da una proximidad mayor con los herederos que con los reproductores. Lo encontramos, por ejemplo, al revisar la existencia de algunos bienes en los hogares. El calefont, por ejemplo, que es un dispositivo de presencia masiva en las viviendas de herederos y primera gene- 
ración, no siempre está presente en los hogares de los reproductores. O el computador, herramienta hoy día casi universal para los herederos y los primera generación, pero no tanto para los reproductores. Y así también con el acceso a tecnologías de la información y comunicación en los hogares, en que el distanciamiento de los primera generación con respecto a los reproductores se repite e incluso agudiza. Es el caso del celular, la smart-tv o el Internet banda ancha fija, presente en el $61 \%$ de los hogares de los primera generación y el $71 \%$ de los herederos, pero solamente en el 32\% de los hogares de reproductores - esto por desinterés tecnológico, pero sobre todo por el alto costo de los aparatos y las conexiones.

GRÁFICO 14. PRESENCIA DE BIENES EN EL HOGAR SEGÚN GRUPO GENERACIONAL $(\%)$

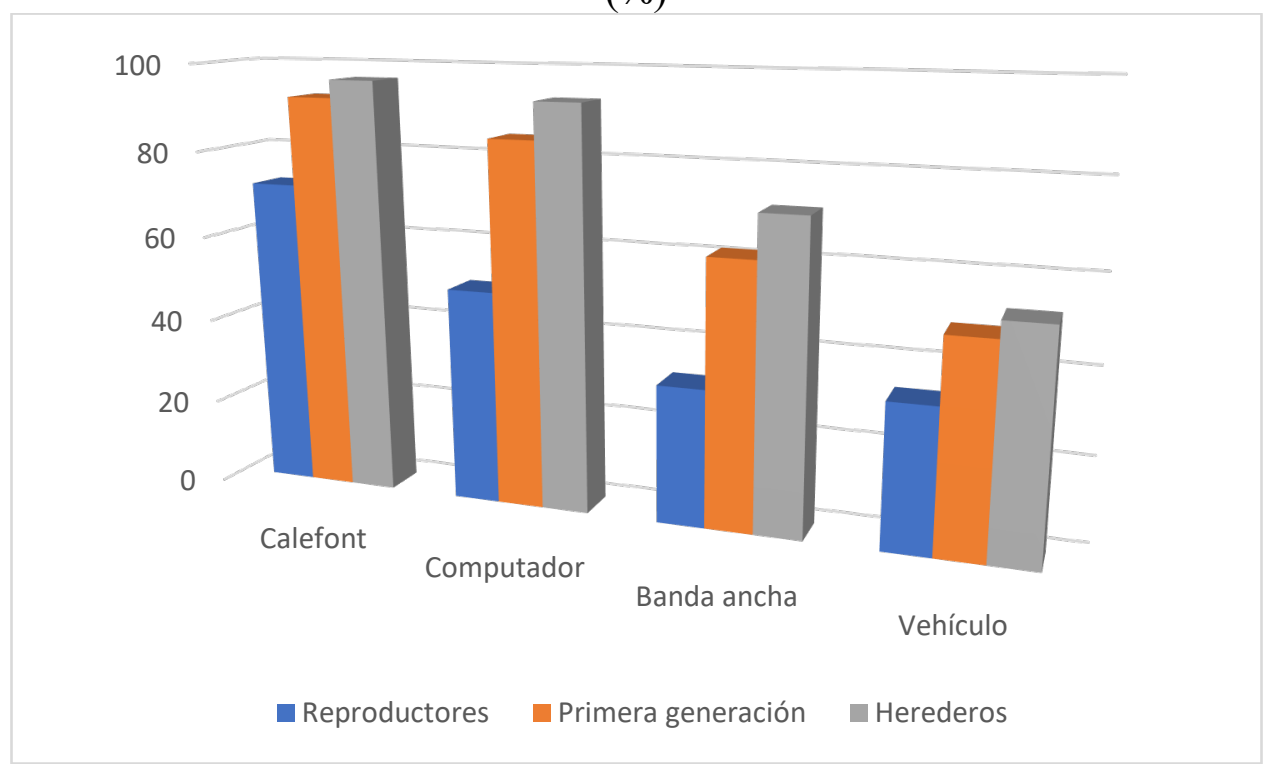

Fuente: Elaboración propia sobre la base de Casen 2017.

Y es el caso, por último, del automóvil, artículo icónico, como pocos, de acceso al consumo. Como con las viviendas, las tecnologías y otros bienes, en el caso de los automóviles encontramos la misma partición: los reproductores en la base, con la frecuencia más baja, los herederos en la cima, y en el medio, poco más abajo, los primera generación. Y lo interesante aquí es lo que sucede con la edad. Antes de los 30 años, los tres grupos presentan situaciones relativamente parejas. Entre los 25 y 29 años hay más primera generación $(39,9 \%)$ y herederos $(36,9 \%)$ que ya tienen un automóvil, pero no se distancian mucho de 
los reproductores $(29,9 \%)$; pero al pasar a los 30-35 años, el porcentaje de reproductores con auto se mantiene relativamente estable - llega al 35,5\%-, mientras en herederos y primera generación sube de manera significativa, invirtiendo, de hecho, la situación del tramo etario anterior $(64,3 \%$ y $54,5 \%$, respectivamente).

\subsection{PobreZA}

Buena parte de todo lo anterior queda resumido en la situación de pobreza. Las últimas encuestas Casen han venido ampliando la gama de variables y dimensiones para medirla. A la forma básica centrada en los ingresos se han agregado la pobreza multidimensional —que incluye variables de educación, trabajo y seguridad social, vivienda y salud-, y la pobreza en cinco dimensiones - que agrega una serie de variables que describen las características sociales del entorno en que se habita- (Ministerio de Desarrollo Social, 2016). Cualquiera sea la modalidad, empero, se descubre la misma forma. Por un lado, los reproductores, con las tasas más altas de pobreza y, por el otro, los primera generación y los herederos, con tasas considerablemente más bajas, no superiores al 4,4\% en su registro máximo. Es en este plano donde quizás se hace más notoria la distancia entre reproductores y primera generación y la cercanía relativa de este grupo con los herederos. En todas las formas de medir la pobreza, los primera generación superan a los herederos, pero su proximidad es mucho mayor con este grupo que con los reproductores. Y tanto o más relevante es que esa brecha se agranda conforme se van agregando dimensiones y se complejiza la medición de la pobreza. 


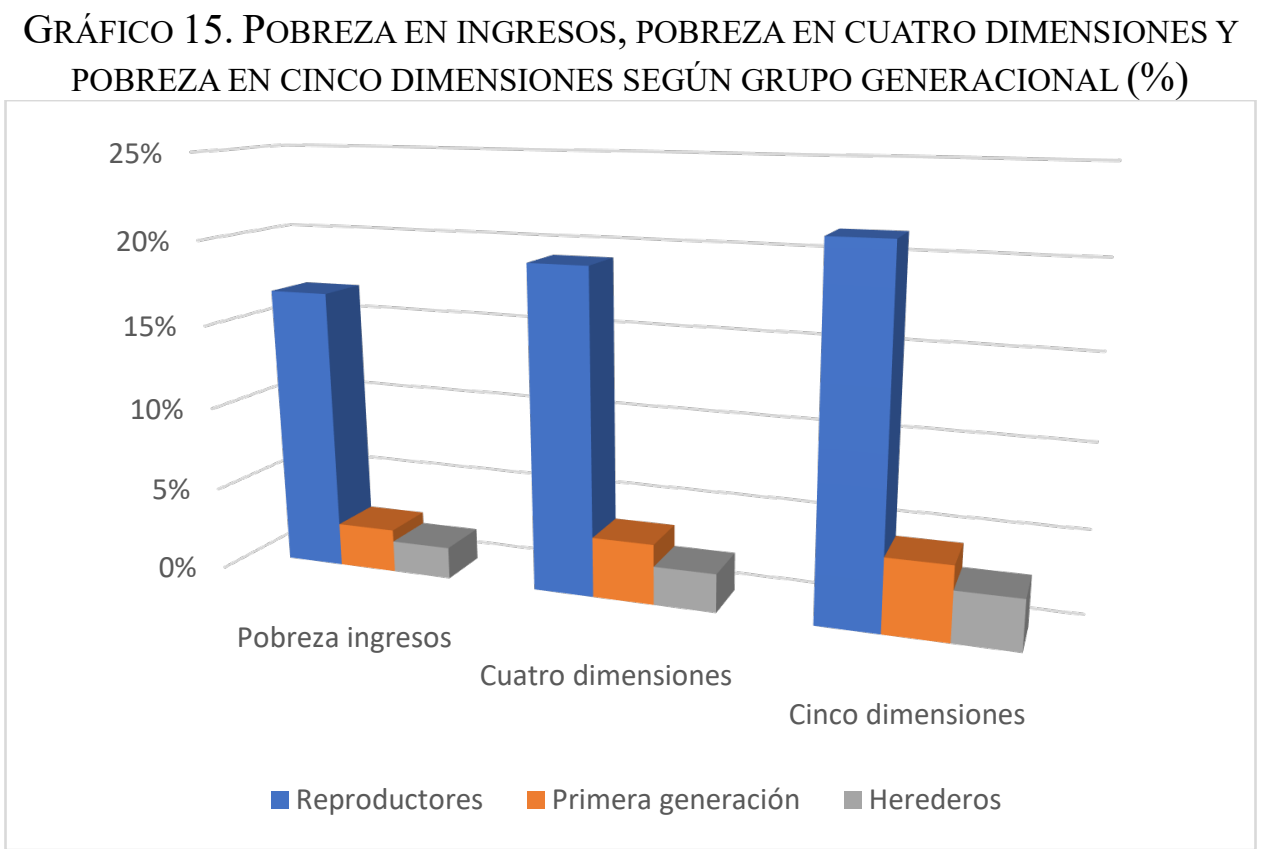

Fuente: Elaboración propia sobre la base de Casen 2017.

\section{CONCLUSIONES Y DISCUSIÓN}

Todo lo expuesto en los puntos precedentes converge, por lo tanto, hacia los mismos puntos comunes. Por un lado, muestra que aquellos nuevos estudiantes de educación superior que fueron primera generación con estudios superiores efectivamente han logrado distanciarse de sus pares de origen tanto en términos laborales como socioeconómicos. El hecho de estudiar ha implicado, en efecto, niveles de ingreso más altos y un horizonte de expectativas expansivo conforme vayan avanzando en edad y se afiance su carrera profesional.

Sugiere, a la vez, que el acceso a educación superior ha sido especialmente relevante para las mujeres, que han logrado encontrar espacios de desarrollo profesional importantes —el sistema de salud, en particular-, y así emparejar, en parte, su situación con respecto a los hombres y distanciarse, al mismo tiempo, de unos quehaceres del hogar que, sin estudios, habrían sido un destino probable.

Pero los resultados sugieren que este proceso tendría sus límites. Desde la elección de las carreras hasta la distribución de puestos laborales se observa que si, por un lado, los primera generación se distancian de los reproductores, mantienen, de todos modos, una distancia relativa con quienes provienen de familias cuyos padres ya eran profesionales. La diferencia entre el volumen de 
técnicos y profesionales en uno y otro grupo y la diferencia de magnitud respectiva en carreras como medicina, derecho o ingeniería civil son, en este sentido, dos modos en que se expresa esta diferencia. Y lo mismo se pudo hallar al analizar los ingresos o el acceso a vivienda y otros bienes de consumo durables. De ahí que el recurso a estas categorías analíticas sirva para aproximarse a un proceso de reconfiguración de la estructura social que está en curso. La emergencia de un grupo generacional que accedió por primera vez a estudios superiores habría producido una fragmentación en sectores de baja escolaridad histórica que probablemente se traduzca en una reconfiguración de las posiciones de clase. Gracias a los estudios, este segmento ha entrado a disputar espacios laborales antes reservados a los sectores más cualificados, distanciándose laboral y socioeconómicamente de sus pares de origen. Su trayectoria replica, en cierto modo, la ruta de las primeras generaciones de la clase media, con la pedagogía y el empleo en el sector público como ejes fuertes, pero aprovechando, al mismo tiempo, los nuevos puestos abiertos por la expansión en los servicios y por el recurso a las nuevas tecnologías. Algunos han logrado incluso entrar en áreas antes reservadas para las élites, como en el caso del derecho, o en profesiones liberales de alto retorno, como la medicina y la ingeniería civil, aunque los antecedentes sugieren que este tipo de carreras y puestos de trabajo «tradicionales»y de alto retorno en ingresos siguen siendo patrimonio principal de las segundas, terceras o más generaciones de profesionales. Además, el relativamente alto porcentaje de estudiantes de primera generación en puestos de ventas y otros empleos de baja cualificación no deja de ser relevante, pensando en las posibilidades reales de inserción en puestos acordes a los estudios alcanzados.

Habría que ver con más detalle este tipo de cuestiones. Estudiar hasta qué punto la condición socioeconómica de origen o el tipo específico de título profesional explican las diferencias socioeconómicas y si se puede avanzar hacia esquemas explicativos más amplios y complejos. Sería importante avanzar con más detalle en el estudio de las diferencias de género, la zona de residencia e incluir a quienes no son jefes de hogar, cuestión imposible con la actual formulación de la encuesta Casen. Particularmente importante sería abordar, además, el ámbito de la subjetividad de estos grupos, el plano de las experiencias y visiones de mundo y sociedad, para ver si estas transformaciones estructurales de la educación y el trabajo en Chile están generando o no sujetos y actores de nuevo tipo. Nos parece que trabajar con estas categorías demuestra ser una buena entrada para mensurar y entender los efectos de un proceso de una magnitud y velocidad tan significativas como la masificación de la educación superior en Chile. 
RECIBIDO: 21 DE JUNIO DE 2019

ACEPTADO: 9 DE DICIEMBRE DE 2019

\section{BiBLIOGRAFÍA}

ARMANET, P. (2005). Formación universitaria para el siglo XXI. En Foco, 44.

BOURDIEU, P. y PASSERON, J.-C. (1996). La reproducción. Elementos para una teoría del sistema de enseñanza. México, D. F.: Fontamara. . (2003). Los herederos. Los estudiantes y la cultura. Buenos Aires: Siglo XXI.

CAstillo, J. y CABEZAS, G. (2010). Caracterización de jóvenes primera generación en educación superior. Calidad en la Educación, 32.

. (2012). IX Encuesta Actores del sistema educativo. Centro de Investigación y desarrollo de la Educación, Universidad Alberto Hurtado. Santiago.

Cataldi, E., Bennett, C. y Chen, X. (2108). First-Generation Students: College Access, Persistence, and Postbachelor's Outcomes. Washington, D. C.: National Center for Education Statistics.

Chen, X. (2005). First-Generation Students in Postsecondary Education: A Look at their College Transcripts. Washington, D. C.: National Center for Education Statistics.

Choy, S. (2001). Students Whose Parents Did Not Go to College: Postsecondary Access, Persistence, and Attainment. Washington, D. C.: National Center for Education Statistics.

COLLIER, P. y Morgan, D. (2008). «Is that paper really due today?»: differences in first-generation and traditional college students' understandings of faculty expectations. Higher Education, 55.

Concha, C. (2009). Sujetos rurales que por primera generación acceden a la universidad. Calidad en la Educación, 30.

Davis, J. (2010). The First Generation Student Experience: Implications for Campus Practice. Stylus Publishing.

Engle, J. y Tinto, V. (2008). Moving Beyond Access. College Success For Low-Income, First-Generation Students. Washington, D. C.: The Pell Institute. 
ESPRÍVALO, P. y SCOTT, W. (2003). Ready or not, here we come: retaining hispanic and first-generation students in postsecondary education. Соттunity College Journal of Research and Practice, 27, 147-156.

Flanagan, A. (2017). Experiencias de estudiantes de primera generación en universidades chilenas: realidades y desafíos. Revista de la Educación Superior, 46, 87-104.

Gofen, A. (2009). Family Capital: how First-Generation Higher Education Students break the intergenerational cycle. Famility Relations, 58, 104120.

Hicks, T., ButLer, D. y MYrick, M. (2019). First-Generation College Student Research Studies. London: Hamilton Books.

Hodge, A. y Mellin, E. (2010). First-generation college students: The influence of family on college experience. The Penn State McNair Journal, 7, 120-134.

JARPA, C. y RodRíGUEZ, C. (2017). Segmentación y exclusión en Chile: el caso de los jóvenes primera generación en educación superior. Revista Latinoamericana de Ciencias Sociales, Niñez y Juventud, 15, 327-343.

LOHFInK, M. y PAUlsen, M. (2005). Comparing the Determinants of Persistence for First-Generation and Continuing-Generation Student. Journal of College Student Development, 46(4), 409-428.

London, H. (1989). Breaking Away: A Study of First-Generation College Students and Their Families. American Journal of Education, 97(2), 144170 .

. (1992). Transformations: Cultural Challenges Faced by FirstGeneration Students. New Directions for Community Colleges, 80, 5-11.

Lowery-Hart, R. y George PACheco, G. (2011). Understanding the first-generation student experience in higher education through a relational dialectic perspective. New Directions for Teaching and Learning, $127,55-68$.

Mehta, S., Newbold, J. y O'Rourke, M. (2011). Why Do First-Generation Students Fail? College Student Journal, 45(1), 20-35.

Nunez, A. y Cuccaro-Alamin, S. (1998). First-Generation Students: Undergraduates Whose Parents Never Enrolled in Postsecondary Education. Washington, D. C.: National Center for Education Statistics.

ORBE, M. (2004). Negotiating multiple identities within multiple frames: an analysis of first-generation college students. Communication Education, $53,131-149$.

Orellana, V. (2011). Nuevos y viejos profesionales en Chile. Impacto de la educación superior en la estructura social (1983-2010), elementos para 
una interpretación sociológica. (Tesis para optar al título profesional de sociólogo). Departamento de Sociología, Universidad de Chile, Santiago.

Pascarella, E., Pierson, C., Wolniak, G. y Terenzini, P. (2004). Firstgeneration college students: Additional evidence on college experiences and outcomes. The Journal of Higher Education, 75, 249-284.

PIKE, G. y KUH, G. (2005). First and second-generation college students: A comparison of their engagement and intellectual development. The Journal of Higher Education, 76, 276-300.

Próspero, M. y Vohra-Gupta, S. (2007). First Generation College Students: Motivation, Integration, and Academic Achievement. Community College Journal of Research and Practice, 31, 963-975.

Ramos, C. (2018). Decisiones educativas y valoración de la educación superior en la trayectoria académica de los profesionales primera generación universitaria. (Memoria para optar al título profesional de socióloga). Universidad de Chile, Santiago.

SoriA, K. y Stebleton, M. (2012). First-generation students' academic engagement and retention. Teaching in Higher Education Critical Perspectives, 17, 673-685.

Soto, V. (2016). Estudiantes de primera generación en Chile: una aproximación cualitativa a la experiencia universitaria. Revista Complutense de Educación, 27(3), 1157-1173.

Terenzini, P., Springer, L., Yaeger, P., Pascarella, E. y Nora, A. (1996). First-generation college students: Characteristics, experiences, and cognitive development. Research in Higher Education, 37, 1-22.

Warburton, E., Bugarin, R. y Nuñez, A. (2001). Bridging the Gap: Academic Preparation and Postsecondary Success of First-Generation Students. Washington, D. C.: National Center for Education Statistics. 